\title{
Glycaemic index methodology
}

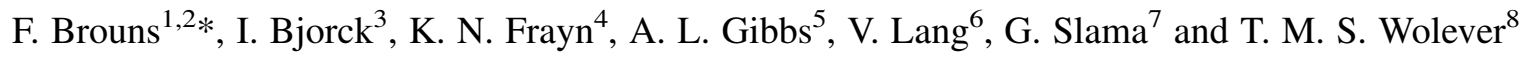 \\ ${ }^{1}$ Maastricht University, Nutrition and Toxicology Research Institute, Department of Human Biology, \\ PO Box 616, 6200MD, Maastricht, The Netherlands \\ ${ }^{2}$ Cerestar- Cargill R\&D Center, Vilvoorde, Belgium \\ ${ }^{3}$ University of Lund, Department of Applied Nutrition and Food Chemistry, Lund, Sweden \\ ${ }^{4}$ OCDEM, University of Oxford, Oxford, UK \\ ${ }^{5}$ Department of Statistics, University of Toronto, Toronto, Ontario, Canada \\ ${ }^{6}$ Danone Vitapole R\&D Center, Palaiseau CEDEX, France \\ ${ }^{7}$ INSERM - Unité 341, Département Diabète, Paris CEDEX 04, France \\ ${ }^{8}$ Department of Nutritional Sciences, University of Toronto, Toronto, Ontario, Canada
}

\begin{abstract}
The glycaemic index (GI) concept was originally introduced to classify different sources of carbohydrate (CHO)-rich foods, usually having an energy content of $>80 \%$ from $\mathrm{CHO}$, to their effect on post-meal glycaemia. It was assumed to apply to foods that primarily deliver available $\mathrm{CHO}$, causing hyperglycaemia. Low-GI foods were classified as being digested and absorbed slowly and high-GI foods as being rapidly digested and absorbed, resulting in different glycaemic responses. Low-GI foods were found to induce benefits on certain risk factors for CVD and diabetes. Accordingly it has been proposed that GI classification of foods and drinks could be useful to help consumers make 'healthy food choices' within specific food groups. Classification of foods according to their impact on blood glucose responses requires a standardised way of measuring such responses. The present review discusses the most relevant methodological considerations and highlights specific recommendations regarding number of subjects, sex, subject status, inclusion and exclusion criteria, pre-test conditions, $\mathrm{CHO}$ test dose, blood sampling procedures, sampling times, test randomisation and calculation of glycaemic response area under the curve. All together, these technical recommendations will help to implement or reinforce measurement of GI in laboratories and help to ensure quality of results. Since there is current international interest in alternative ways of expressing glycaemic responses to foods, some of these methods are discussed.
\end{abstract}

Glycaemic index: Carbohydrates: Blood glucose response: Classification of foods: Glycaemic response: Glycaemic load

\section{Introduction}

The glycaemic index (GI) concept was originally introduced as a means of classifying different sources of carbohydrate (CHO) and CHO-rich foods in the diet, according to their effect on postprandial glycaemia (Jenkins et al. 1981). It was assumed to apply to foods that primarily deliver available $\mathrm{CHO}$ such as potatoes, rice, cereals, etc. usually having an energy content of $>80 \%$ from $\mathrm{CHO}$. The usual $50 \mathrm{~g} \mathrm{CHO}$ test load has traditionally referred to available $\mathrm{CHO}$ providing sugars for absorption from the small intestine at a certain rate. As such, low-GI $\mathrm{CHO}$ were classified as those that are digested and absorbed slowly and lead to a low glycaemic response, whereas high-GI CHO are rapidly digested and absorbed and show a high glycaemic response. This relationship between the rate of digestion and absorption and glycaemic response is also shown using various in vitro digestion models that mimic the in vivo situation. A very high correlation exists between the rate of in vitro glucose release from starchy foods, using pancreatic and brush-border enzymes, and the glycaemic response in vivo (Granfeldt et al. 2005; Englyst et al. 2003). Recently various food factors that may influence in vivo absorption and to a certain degree affect the outcome of GI values were summarised by Arvidsson-Lenner et al. 2004 (see Table 1).

The rate of glucose entry into blood and the duration of the elevated blood glucose is known to induce many hormonal and metabolic changes that may affect health and 
Table 1. Food factors affecting the glycaemic response of foods and meals (adapted from Arvidsson-Lenner et al. 2004)

\begin{tabular}{llc}
\hline Food factor & Examples of influencing factors & Effect on glycaemic response and glycaemic index \\
\hline Gross matrix structure & Grinding & Higher when homogenised \\
Cell-wall and starch structure & Degree of ripening & Higher with ripening \\
Granular starch structure & Heat treatment & Higher when gelatinised \\
Amylose and amylopectin & Amylopectin is branched and more & Higher with increased amylopectin content \\
content & rapidly digestible than amylose & Reduced \\
Gelling dietary fibre content & Added gelling fibres & Reduced \\
Organic acids, e.g. acetic acid & Added acids & Reduced \\
Amylase inhibitor & Added & Reduced with increased fructose content \\
Monosaccharide composition & Type of added sugars, e.g. glucose:fructose ratio & Reduced with increased number of bonds other \\
Molecular composition of & Type of raw material & than $\alpha 1-4$ and $\alpha 1-6$ \\
carbohydrate & Type of monosaccharide & Indifferent when testing equal amounts of available \\
Resistant starch content & beating-cooling cycles & carbohydrate
\end{tabular}

disease parameters. In this respect, low-GI foods were often found to induce benefits on risk factors for certain chronic diseases. Because of these observations it was proposed that GI data for foods could be used to make priorities for food selection within food groups.

Meanwhile, many studies have examined the short-term biological and health effects of foods, meals and diets of varying GI (Jenkins et al. 1987; Brand-Miller, 1994; Wolever \& Bolognesi, 1996a; Järvi et al. 1999; Kaplan et al. 2000; Foster-Powell et al. 2002; Benton et al. 2003; Wolever \& Mehling, 2003). More recently, intervention studies were developed (Brand et al. 1991; Frost et al. 1994, 1998; Giacco et al. 2000; Gilbertson et al. 2001; Wolever \& Mehling, 2002; Bouché et al. 2002; Rizkalla et al. 2004) and some epidemiological studies based on prospective cohorts have provided new conclusions about the possible implications of GI on health; for example, diabetes (Salmeron et al. 1997a,b; Meyer et al. 2000), CVD (Frost et al. 1999; Liu et al. 2000, 2001; van Dam et al. 2000) and cancer (Slattery et al. 1997; Augustin et al. 2001, 2003; Franceschi et al. 2001; Jenkins \& Franceschi, 2001). GI may also have relevance for sports performance (Thomas et al. 1991), appetite control (Holt et al. 1996) and cognitive performance (Benton et al. 2003), whereas its role for obesity has recently been debated (Pawlak et al. 2002; Raben, 2002).

Recently Livesey (2002) addressed the effects of low- and high-glycaemic meals and diets on health and disease-related parameters. Based on recent observations it is expected that reductions in daily glycaemic load (GL) may lead to a reduced risk for developing diabetes and CVD. For example, Salmeron $(1997 a, b)$ showed that the GL of the daily diet correlates with the risk of developing diabetes in women but not in men. Brand-Miller et al. (2003a) observed a clinically significant decrease of protein glycation with a reduction of GL of the diet. Such observations encompass the potential to reduce the glycaemic response to foods by such means as the substitution of available $\mathrm{CHO}$ with indigestible or nonavailable $\mathrm{CHO}$ or with protein and/or fat. In contrast, in the Framingham Offspring Cohort it was recently demonstrated that whole-grain intake is inversely associated with homeostasis model assessment of relative insulin resistance (HOMA-IR), and a lower prevalence of the dysmetabolic syndrome, whereas dietary GI, but not GL, is positively associated with HOMA-IR and the prevalence of the dysmetabolic syndrome (McKeown et al. 2004). According to Brand-Miller (2004), the quality of CHO (i.e. GI) more often shows a significant association with disease risk (diabetes, CVD, cancer) than does the CHO content or GL of the diet. Very recently, several other papers and reviews addressed the impact of GI and GL on health aspects (Tavani et al. 2003; Frost et al. 2004; Kelly et al. 2004; Opperman et al. 2004). No benefits occurred in the Frost study, but according to the authors it cannot be excluded that potential effects may have been concealed due to drug therapy. In the Tavani study, a higher GI slightly increased risk for acute myocardial infarction but only in elderly individuals (more than 60 years) in association with overweight. On the other hand, the meta-analysis by Opperman et al. (2004) supports the value of low-GI foods to lower total cholesterol and improve metabolic control of diabetes. The benefits in the Kelly study were modest, and appeared mainly on total cholesterol and glycated haemoglobin. Based on the publications listed above there is accumulating evidence (Brand-Miller, 2004) that diets containing a preponderance of foods that elicit low glycaemic responses ('low-GI foods or diets'), as originally defined by Jenkins et al. (1981) induce modest to clinically important benefits in the intermediate term as shown by intervention studies, and from epidemiological studies of health benefits in the longer (6-10 year) term.

Various authors studied the impact of variations in some methodology-related variables on the obtained GI value. This has led to review papers (Wolever, 1990a; Wolever et al. 1991), which discussed the influence of methodological variation and provided several recommendations for GI measurement. More recently the methodology of measuring GI was discussed by an expert panel, as part of a global discussion on the role of dietary CHO in nutrition (Food and Agriculture Organization, 1998). This panel agreed on a reference methodology and provided guidelines for measurement in future GI testing. In line with this development, there is an increasing number of foods which have been characterised regarding glycaemic response as attested by the last version of the international table of GI (Foster-Powell et al. 2002). Increasing information is also at hand regarding the food mechanisms responsible for differences in GI between foods and 
modulation of GI of foods (Björck et al. 2000; Augustin et al. 2002; Bjorck \& Elmstahl, 2003).

There is also a growing interest in GI from research, public health and industrial bodies. Recently, the FAO and WHO recommended that the bulk of CHO should be of low GI and rich in NSP (Food and Agriculture Organization, 1998) In several countries (Australia, France, Sweden, Canada and South Africa), the use of the GI concept has been integrated in dietary guidelines given by health professionals, and an increasing number of food companies market low-GI products. In line with these developments there is an increasing interest in the measurement of glycaemic response and GI of foods by a large number of academic and commercial laboratories, for both research and commercial application purposes.

\section{The glycaemic index concept, as any concept, has 'pros' and 'cons'}

Recently there has been debate on the accuracy of some aspects of the method for the measurement of GI. This was summarised by Pi-Sunyer (2002) and Monro (2003). In addition, there are other ways of describing glycaemic responses of foods or drinks of mixed macronutrient composition, such as the glycaemic glucose equivalent (GGE; Monro, 2002, 2003), which ultimately is an index that arguably more closely represents food portion sizes, and GL (GL refers to the product of the amount of available CHO in a certain amount of food and its GI, divided by 100 ; Liu et al. 2003). These enable an index of glycaemic effects to be assigned to all types of food.

Another issue relates to CHO types (Asp, 1995) and analytical methods. According to the current physiological definition of dietary fibre (Champ et al. 2003), all indigestible $\mathrm{CHO}$ are considered to be dietary fibre; thus also resistant starch (RS), non-digestible oligosaccharides and sugar alcohols (polyols). Yet the classical method of measuring dietary fibre did not measure these $\mathrm{CHO}$ appropriately, leading to an underestimation of the true content of unavailable $\mathrm{CHO}$ in foods and diets. The question 'has this influenced the presently published GI values of foods' (Foster-Powell et al. 2002) is valid in this respect. It should be noted, though, that the majority of commercial foods included in the international GI tables contain low levels of these sources of indigestible $\mathrm{CHO}$.

Thus, it is acknowledged in this respect that it is impossible to answer all questions, as the required data are not always available. It is also acknowledged that alternative concepts of communicating the glycaemic responses to foods and mixed meals might be more appropriate to inform healthy consumers as well as patients, including diabetics, about the health impacts of this aspect of their diets. In all cases, however, long-term studies (and none less than 8 weeks) are needed to establish the extent, nature and circumstances of health benefits, this including studies on GI. The current intensified interest in glycaemic response will undoubtedly lead to further progress of refining or extending the current methods as well as of defining the best measure for clinical and epidemiological research.

Since there are differing opinions on various aspects of measuring glycaemic response to foods and drinks and the possible use of a descriptive value to support well-informed food and drink choices, there is a need for consensus on the methodology of measuring glycaemic responses and converting the results to comparative values (ArvidssonLenner et al. 2004; Laville, 2004). Therefore, in the present paper we aim at discussing frequently asked questions on how to measure a glycaemic response and calculate a GI value according to the classical GI method appropriately. We provide information about the scientific backgrounds, the methodological steps to be preferred, and comment on how deviations can be accepted without detrimental effect to the results. We describe key criteria related to choice of an appropriate control, number of subjects, the importance of comparing equal amounts of available $\mathrm{CHO}$ and how to deal with determination and description of these. We also give recommendations for future research and further developments related to measuring the glycaemic response to foods and drinks in our daily diet and its possible impact on health and disease.

\section{Questions on methodological aspects of glycaemic index}

\section{Subject number}

How many subjects should be enrolled?

Scientific background. As in all studies, the number of subjects enrolled determines, in part, the width of the CI for the estimates obtained, and the power of the study to detect differences in GI. Using more subjects provides better power and more precise results, but at a higher cost. The CI and experimental power of a study depend upon the number of subjects studied and the variability of the endpoint measured. A recent interlaboratory study (Wolever et al. 2003), in which GI values of five foods were determined in forty-seven subjects, provided a reasonable estimate of the inherent variability of results from GI determinations. The SD of GI values were linearly related to their means (Fig. 1). Thus, the width of the CI and power analysis for GI values depends not only on the number of subjects but also on the mean GI. Fig. 2 shows half-widths (or margins of error) of $95 \%$ CI by number of subjects and mean GI in healthy individuals for GI values based on glucose (i.e. the GI

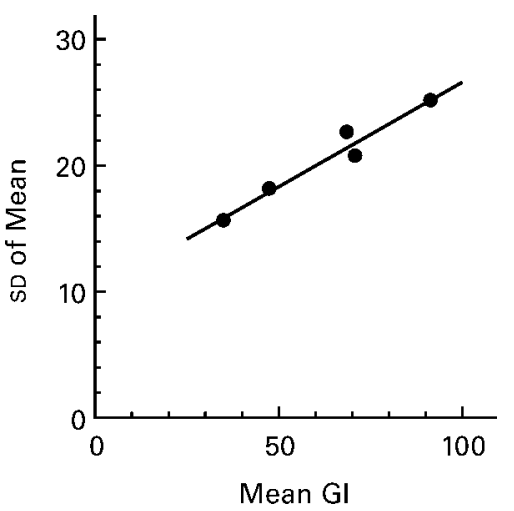

Fig. 1. Relationship between mean glycaemic index (GI) and SD of GI values of five foods determined in forty-seven subjects (Gl of glucose $=100)$ (from Wolever et al. 2003) 


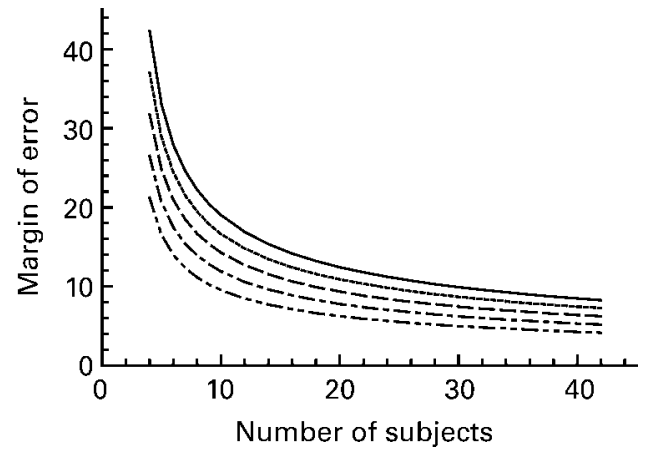

Fig. 2. Estimated margins of error for $95 \% \mathrm{Cl}$ of glycaemic index (Gl) values by number of subjects and mean Gl (Gl of glucose $=100) .(-), \mathrm{Gl}=100 ;(\cdots), \mathrm{Gl}=80 ;(--), \mathrm{Gl}=60 ;(----)$, $\mathrm{GI}=40 ;(---), \mathrm{Gl}=20$.

of glucose $=100)$. Fig. 3 shows the difference in GI that can be detected with $80 \%$ power at a level of $P<0.05$ (twotailed) by number of subjects and mean GI. It can be seen that use of ten subjects provides useful results; large improvements in power and precision would require two to three times more subjects.

To further examine this question, a simulation analysis was carried out to examine the effect of sample size on the variability of the precision of estimates of the mean GI. The simulation used data from the thirty-seven subjects from whom capillary blood was taken and who performed exactly three repeats of the reference food glucose (Wolever et al. 2003). For each of the five foods (instant potato, bread, rice, spaghetti and barley), 1000 bootstrap samples of sizes eight, ten, twelve, twenty and thirty-seven (twenty-seven for bread, excluding ten subjects who tested bread repeatedly) were taken from the individual GI values and the corresponding mean and $95 \% \mathrm{CI}$ for the margin of error was calculated for each bootstrap sample (Fig. 4). As can be seen from Fig. 4, the width of $95 \%$ CI, which is an estimate of the precision of the estimated margin of error, decreases with sample size and can vary widely in small sample sizes.

Recommendation. The inclusion of ten subjects provides a reasonable degree of power and precision for most purposes

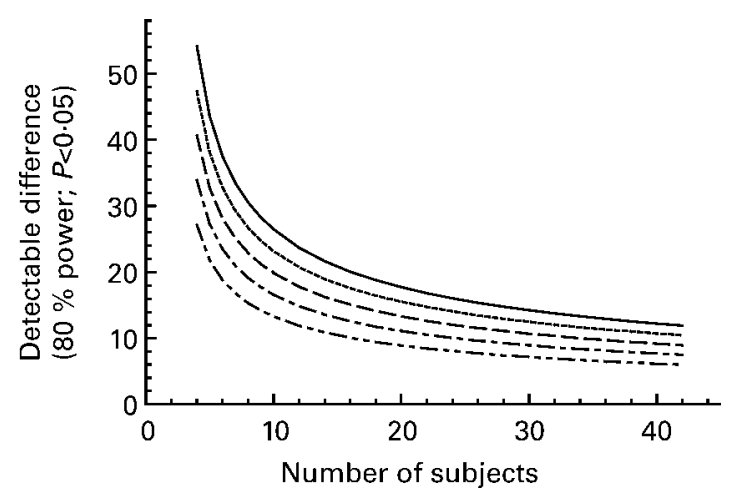

Fig. 3. Estimated difference in glycaemic index (GI) that can be detected with $80 \%$ power with two-tailed $P<0.05$ by number of subjects and mean $\mathrm{Gl}(\mathrm{Gl}$ of glucose $=100) .(-), \mathrm{Gl}=100 ;(\cdots)$, $\mathrm{GI}=80 ;(--), \mathrm{GI}=60 ;(---), \mathrm{GI}=40 ;(----), \mathrm{Gl}=20$. of measuring GI. The number of subjects can be increased if the aim of the study is to detect small differences in GI or when greater precision is required.

\section{Test number}

How many times should the test be replicated for the standard and test foods?

Scientific background. In determining the GI of a series of test foods, the area under the curve (AUC) of the reference food is used as the denominator of every other test food. Precision will be improved if the measurements on the test food and the reference food are repeated among individuals. However, repeating all measurements adds undesirable expense.

Variation in the response to the reference food has greater effect on the results than the corresponding variation in the test foods, because the former is used to calculate the GI value of every test food in the series. Thus, the focus of this discussion will be how many times the reference food trials should be repeated. It is desirable to obtain as representative a value for the AUC for the reference food for each subject as possible. This can be achieved in practice by using the mean value of several trials of the reference food. The average of three trials of the reference food has been shown to reduce the variation of mean GI values (Wolever et al. 1991, 2002). The suggestion to use three repeated trials, as opposed to some other number, was based on a relatively small number of clinical observations. Although not enough real data exist to determine exactly how many repeats of the reference food should be done, both a simulation study and a theoretical argument presented later indicate that two or three measurements are appropriate.

From a theoretical perspective, we are interested in examining how the precision of a ratio of two measurements can be improved by replacing the denominator by the mean of several measurements. Using a linear approximation from a Taylor Series' expansion, an approximate expression for the variance of $Y / X$ is:

$\frac{\mu_{Y}^{2}}{\mu_{X}^{2}}\left(\frac{\sigma_{X}^{2}}{\mu_{X}^{2}}+\frac{\sigma_{Y}^{2}}{\mu_{Y}^{2}}-2 \rho \frac{\sigma_{X}}{\mu_{X}} \frac{\sigma_{Y}}{\mu_{Y}}\right)$,

where $\mu_{X}$ and $\mu_{Y}$ are the means of $Y$ and $X, \sigma_{X}$ and $\sigma_{Y}$ are their standard deviations, and $\rho$ is the correlation between $Y$ and $X$. We will assume that the $\mathrm{CV}(\sigma / \mu)$ are constant and the same for both $Y$ and $X$. We will denote this CV by $\nu$. Replacing $X$ by the mean of $k$ measurements reduces its SD to $\sigma_{X} / \sqrt{k}$ and as a result the SD of the ratio $Y / \bar{X}$ is approximately:

$\sqrt{\frac{\mu_{Y}^{2}}{\mu_{X}^{2}} v^{2}\left(1+\frac{1}{k}-\frac{2 \rho_{k}}{\sqrt{k}}\right)}$,

where $\rho_{k}$ is the correlation between $Y$ and the mean of the $k$ values of $X$. It should be noted that as $k$ increases, so will the correlation $\rho_{k}$. Our goal is to minimise the SD of the ratio. For the interlaboratory study (Wolever et al. 2003), correlations between test food and reference food AUC measurements were typically 0.6 to 0.7 . As an approximation, if we fix $\rho_{k}$ at $0 \cdot 6$, the ratio SD is minimised for $k=2.78$ and for $\rho_{k}=0.7$, 


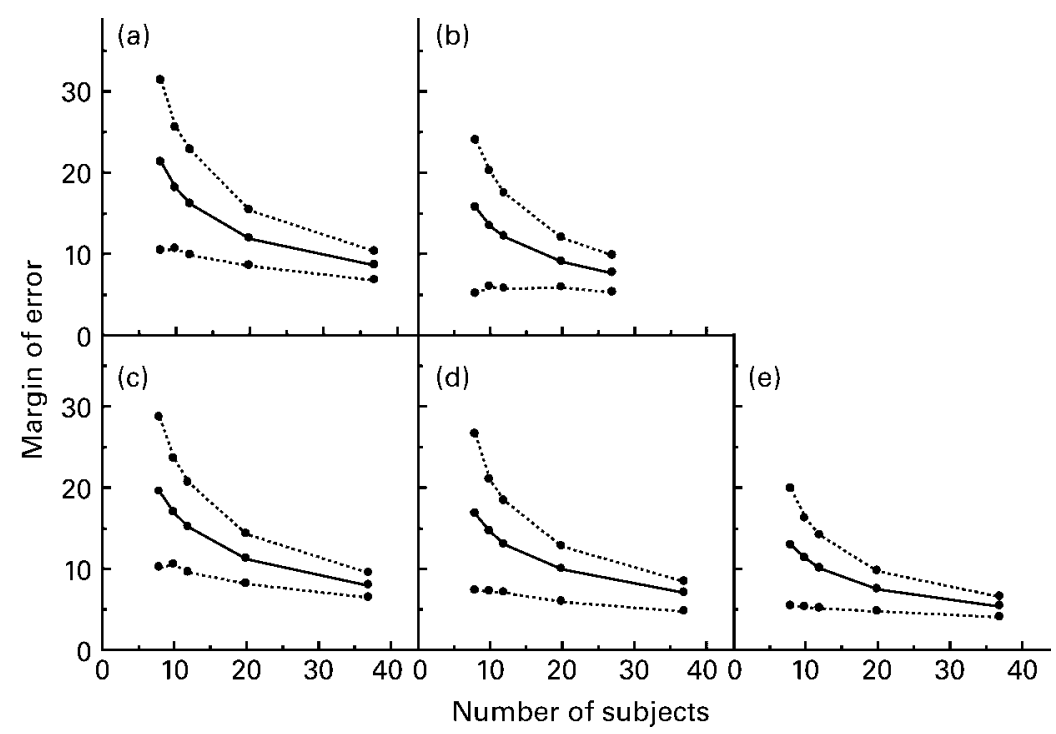

Fig. 4. Bootstrap estimates (-•-) and $95 \% \mathrm{Cl}(\ldots \bullet \cdot)$ ) for the margins of error of $95 \% \mathrm{Cl}$ for mean glycaemic index (Gl) for five foods (potato (a), bread (b), rice (c), spaghetti (d), barley (e)) for different numbers of subjects (Gl of glucose $=100)$.

the SD is minimised for $k=2 \cdot 06$, i.e., a minimum of two reference food measurements should be taken and three measurements is appropriate when the correlation in AUC measurements between the reference and test foods is more moderate.

In order to get a further indication of the effect of the number of reference food measurements on the precision of the resulting estimates of GI, a simulation study was carried out based on the data of Wolever et al. (2003). The CV of glucose AUC values was assumed to be constant over all subjects, and taken to be the pooled value of $\mathrm{CV}$ for all thirty-seven subjects for whom there existed exactly three repeated trials of oral glucose (reference food) and from whom capillary blood was taken. This pooled CV was $27.9 \%$. For each subject, a number of AUC values were simulated from a normal distribution whose mean was the mean AUC elicited by oral glucose (reference food) for that subject and whose CV was the pooled estimate. The observed AUC values for five foods (instant potato, bread, rice, spaghetti and barley) were divided by the mean of the simulated responses to the reference food to give the GI. Based on the resulting GI, the margin of error (the halfwidth) for a $95 \%$ CI was calculated. The analysis was run using one or the average of two, three, four, five, ten and 100 simulated repeated values of the reference food. The results are shown in Fig. 5. The margin of error of the estimate of mean GI decreased substantially from one to two reference measurements. There was virtually no benefit to be gained from taking more than three to four measurements of the reference food AUC. The decrease in the margin of error from one to two reference foods is statistically significant; there are no statistically significant differences among the margins of error for any other number of reference food measurements.

Recommendation. We recommend repeating the trials of the reference food at least once, to obtain at least two values, in each subject.

\section{Subject status}

What should be the physiological or pathophysiological status of the subject?

Scientific background. As it is known that subject characteristics such as the insulin sensitivity and glucose tolerance status influence the glycaemic response to a food, it is of interest whether the physiological or pathophysiological status of the subjects needs to be considered for reasons of precision and comparability of GI values, as well.

Theoretically, the highest precision of GI values is expected when the within-subject variation of the incremental AUC of the blood glucose response is minimised. The variability of the glycaemic response to the same food tested on several occasions by the same subject can be expressed as the $\mathrm{CV}(\mathrm{CV}=\mathrm{SD}$ as a percentage of the mean). This question was addressed in one study that compared the average $\mathrm{CV}$ of glycaemic responses for repeated tests of white bread of subjects without diabetes

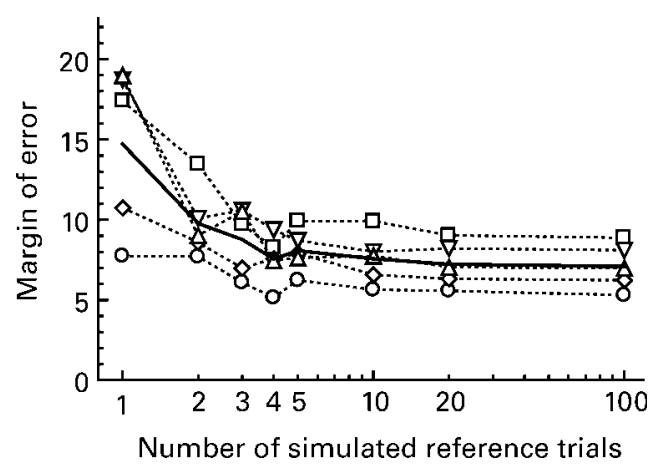

Fig. 5. Margin of error (half-width of $95 \% \mathrm{Cl}$ ) of simulated glycaemic index (Gl) values calculated in thirty-seven subjects in which the area under the curve for the reference food was the mean of 1 to 100 simulated trials (GI of glucose $=100) .(-)$, Mean; $(\cdots \square \cdots)$, potato; $(\cdots \Delta \cdots)$, bread; $(\cdots \nabla \cdots)$, rice; $(\cdots \diamond \cdots)$, spaghetti; $(\cdots \circ \cdots)$, barley. 
with those of subjects with type 2 diabetes and subjects with type 1 diabetes. Subjects with type 2 diabetes displayed significantly less within-subject variation (CV 15\%) than subjects with type 1 diabetes (CV 29\%; $P=0.008)$ with normal subjects being intermediate (CV 22\%) (Wolever et al. 1985; Wolever, 1990a).

The question, whether GI values as relative glycaemic responses (RGR) are still affected by subject characteristics in general and whether GI values obtained in one kind of subjects are comparable or valid in different subjects, was addressed in several studies. Subject characteristics that have been examined specifically and were found to have no significant effect on mean GI include: normal $v$. diabetic subjects (Jenkins et al. 1983); individuals with type 2 diabetes $v$. individuals with type 1 diabetes (Wolever et al. 1987; Livesey, 2002); type 2 diabetic subjects on oral agents $v$. on insulin (Jenkins et al. 1986); type 2 diabetic subjects in good $v$. poor metabolic control (Wolever et al. 1986b); children with type 1 diabetes $v$. adults with type 1 diabetes (Wolever et al. 1988a; Livesey, 2002); rural African v. normal Western subjects (Jenkins et al. 1981; Walker \& Walker, 1984); glucose tolerance status and BMI (Wolever, 1990a; Wolever et al. 1998).

Recommendation. Subject characteristics do not appear to have a significant effect on mean GI values but the variation of the values may differ in various groups, being highest in individuals suffering from type 1 diabetes. Therefore, for routine testing, healthy human volunteers are recommended.

\section{What should be the reference food?}

Scientific background. A variety of foodstuffs have been used as reference for GI measurement. In the updated GI database (Foster-Powell et al. 2002), we counted ten different reference foods for almost 1300 measurements: glucose, bread, white bread, wholemeal barley bread, wheat chapatti, potato, rice, wheat and arepa (a Mexican starchy food). However, most of the measurements were done using glucose or white bread as the reference food $(>90 \%$ of studies)

In studies using rice, potato or some other local foods as the reference, these were chosen because of the large part taken by these foods in the local CHO intake. In the case of polyols, sucrose was often used as control as this is usually the $\mathrm{CHO}$ replaced. However, detailed information about the reference foods are sometimes not provided in reports, which limits the applicability of such data in those cases.

Furthermore, the correspondence between the glucoseraising effect of such or many local reference foods and the glucose-raising effect of the frequently studied white bread and glucose reference foods has been poorly studied. This greatly limits comparison of data from different laboratories and experiments, and it also limits dissemination of the results at an international level. By contrast, some laboratories have studied systematically the correspondence between GI on either white bread or glucose reference basis (Sugiyama et al. 2003). Of the reference foods used, bread or glucose have been discussed most. Since bread is a common food, it has been argued that choosing this reference allows the determination of GI in a more physiological manner. However, the composition of white bread may vary from one experiment to another and this may make comparison of results from various experiments difficult. Nevertheless, in a recent interlaboratory study it was concluded that GI values for locally obtained bread are no more variable than those for centrally provided (comparable) foods (Wolever \& Mehling, 2002). In contrast, white bread from a certain local area may differ in GI compared with a common white bread from another area, as happened for the French white bread baguette (FosterPowell et al. 2002). The GI values obtained when white bread is used are typically about 1.4 times those obtained if glucose is used as standard (Food and Agriculture Organization, 1998).

Glucose is sometimes preferred since the $\mathrm{CHO}$ source is more standardised. However, occasionally subjects can get nauseous after taking a concentrated glucose drink in the morning after an overnight fast.

Recommendation. We recommend the index is expressed relative to glucose $=100$. However, for practical purposes, we feel it is acceptable to use reference foods other than glucose (such as white bread) during the measurement of GI. This can be done as long as they have been calibrated against glucose and the condition of preparation of this food is standardised. Dissemination of results should include the calibration data.

\section{Meal volume, composition and consumption time}

(a) Does drink $\mathrm{CHO}$ concentration and osmolarity play a role?

(b) Within how much time do the subjects have to consume the test food?

(c) Should the test-meal volume be adjusted?

Scientific background. The time required for consumption of the test food should allow convenience for the test subjects while minimising effects on gastric emptying rate and feelings of discomfort. The osmolarity of a test drink seems to play no important role but the CHO content does. It was shown that there is a linear relationship between $\mathrm{CHO}$ content of the drink and gastric emptying time. Because of this, the rate of delivery of $\mathrm{CHO}$ from the stomach to the small intestine is fairly constant for soluble available CHO. For example Brouns et al. (1995) observed a constant delivery of about $1.2 \mathrm{~g} \mathrm{CHO} / \mathrm{min}$ for various solutions containing a range of $45-90 \mathrm{~g} \mathrm{CHO} / 1$ and an osmolarity of $243-374 \mathrm{mOsm} / \mathrm{kg}$. Accordingly, the $\mathrm{CHO}$ concentration and osmolarity of the test drinks, at least in the range tested, are not expected to have any impact on glycaemic response.

In the case of foods with low to moderate $\mathrm{CHO}$ density, in order to prevent a too large meal size, the available $\mathrm{CHO}$ content of the test portion is lowered to $25 \mathrm{~g}$ (see question on CHO load; pp. 155-156). Moreover, as the sessions take place in the morning, after a $10-14 \mathrm{~h}$ overnight fast (see question on timing of the test; p. 156), the subjects receive a drink during the test, for their rehydration and comfort. However, even if the amount of drink taken by the subjects is controlled, it differs from one study, or laboratory, to another, being a second source of variation of the volume. 
The determination of the GI of a food usually involves the test of a portion of this food containing $50 \mathrm{~g}$ available $\mathrm{CHO}$ (see later; p. 156). As all foods do not have the same $\mathrm{CHO}$ content, the volume and weight of the test portions varies. Both volume and meal weight will have an impact on the time required for consumption. The question arises as to whether this will influence glycaemic response. It is known for both solid and liquid test meals, in normal and diabetic subjects, that prolonging the time of ingestion from a few minutes to several hours markedly flattens the glycaemic response (Jenkins et al. 1990, 1992). Consuming $75 \mathrm{~g}$ glucose solution over $10 \mathrm{~min}$ as compared with 1 min tended to increase blood glucose 60 to $120 \mathrm{~min}$ later, possibly because of a significantly smaller insulin response during the first $30 \mathrm{~min}$ (Heine et al. 1983). The impact of the volume, $\mathrm{CHO}$ content and osmolarity on gastric emptying has been well studied (Brouns et al. 1995; Brouns, 1998). However, the effect of volume of $\mathrm{CHO}$ foods per se has been poorly studied. Fluids have a strong effect of initial volume on the gastric emptying rate. Accordingly, ingestion time should best be standardised (Brouns, 1998). Unfortunately, the results of studies undertaken to date to evaluate the effect of volume on glycaemic response are contradictory. Some authors found no significant effect of water volume (Gregersen et al. 1990), whereas others observed or indicate a relationship between the volume of water or food and postprandial responses, and sometimes incremental areas (Torsdottir \& Anderson, 1989; Young \& Wolever, 1998; Sievenpiper et al. 2001). These contradictory results could be explained by differences in physiology between diabetic and normal subjects and also by large variations between the protocols used in these studies. Based on current information, it is recommended to avoid potential variability in results due to the amount of drink given to the subjects during the GI testing. Thus, what can be proposed is to give the subjects a standardised amount of drink, such as $250 \mathrm{ml}$ (one glass), without taking into account water included in the food, and the reference used for the GI testing should be $50 \mathrm{~g}$ glucose diluted into $250 \mathrm{ml}$ of water, or a portion of white bread containing $50 \mathrm{~g}$ available $\mathrm{CHO}$ given with $250 \mathrm{ml}$ of a drink

For solid meals the effect of varying time of ingestion over periods of less than $30 \mathrm{~min}$ has not been investigated. Based on practical experience it seems that consumption within $10-15 \mathrm{~min}$ depending on the type of food is appropriate. For example, very sweet foods with a substantial volume may not be consumable for every individual within $10 \mathrm{~min}$.

The first bite or sip in the mouth is set as time 0 and the first blood sample is taken conventionally at exactly $15 \mathrm{~min}$ afterwards.

Other factors. In GI testing, the drink given to the subjects is not always water; coffee or tea have also been used. Young \& Wolever (1998) showed that neither tea nor coffee significantly affect the incremental area under the glycaemic response curve; however, as volume, they influence the pattern of blood glucose response. Moreover, caffeine is known to acutely decrease insulin sensitivity in human subjects (Graham et al. 2000; Keijzers et al. 2002). In the study of Graham et al. (2000), ingestion of $375 \mathrm{mg}$ caffeine resulted in a significant increase in both C-peptide and insulin as well as an increase in the glucose AUC of $24 \%$. Thus, the best drink to administer seems to be water. As a second step, non-energetic or stimulant beverages (coffee, tea) may be supplied as long as an identical quantity and type of beverage is administered during the different sessions of each subject.

Recommendations. We recommend supplying a standard amount of $250 \mathrm{ml}$ water to the subjects with the test portions, and with the white bread portion if it is used as referent. If the referent is glucose, we recommend using a solution of $50 \mathrm{~g}$ glucose diluted into $250 \mathrm{ml}$ water. Fluid ingestion is advised to take place within 5-10 min. Solids and semi-solids should be ingested within 10-20 min, depending on the type and taste of the food. The first blood sample should be taken exactly $15 \mathrm{~min}$ after the first bite of the food or first sip of the drink.

\section{Carbohydrate basis for glycaemic index determination}

Should the test serving be based on available (glycaemic) $\mathrm{CHO}$ ?

Scientific background. In the classical GI concept only CHO sources that are assumed to be fully digestible, absorbable and glycaemic are included in the calculation of the $50 \mathrm{~g} \mathrm{CHO}$ portion size. However, this approach has been criticised for several reasons (Monro, 2003). One is the suggestion that 'available' $\mathrm{CHO}$ is difficult to measure accurately. Accordingly, the usual way of determining 'available CHO', by subtracting 'dietary fibre' from total $\mathrm{CHO}$, is not really a true reflection of in vivo available $\mathrm{CHO}$ content and may lead to overestimation in the case of products containing indigestible $\mathrm{CHO}$, which are not recovered as dietary fibre. Thus, it could be argued that 'available' CHO is only a concept rather than a definable quantity. The truly available $\mathrm{CHO}$ fraction is difficult to determine by in vitro models, since these do not account for any influences within the gastrointestinal tract, for example the fact that some in vitro digestible $\mathrm{CHO}$ may escape small-intestinal digestion and absorption, thus ending unabsorbed in the colon. The analytical aspect is particularly important in the case of starchy foods. Until recently it was difficult to measure the amount of type $3 \mathrm{RS}$ in a food. The former AOAC analytical dietary fibre method did not measure type $3 \mathrm{RS}$ appropriately, leading to some underestimation of the total RS content of many foods in the past. However, in 2002 AOAC recognised an additional new method (McCleary \& Monaghan, 2002) that measures type 3-retrograded RS specifically and accurately.

This analytical progress seems of relevance since an unknown and significant fraction of native starch, once it has been prepared for consumption, may be resistant to digestion. This fraction is usually referred to as intrinsic $\mathrm{RS}$. The amount of RS in a food is further influenced by the food processing and preparation conditions applied as well as by adding RS as a food ingredient. Accordingly, starch may be resistant due to the native (raw and indigestible) botanical structure or starch crystallinity being formed after cooking, during cooling down, by a process called 
retrogradation (formation of indigestible crystalline structures). Alternatively, RS can be added as an ingredient during food processing. The RS content may also change depending on the degree of ripening of a fruit or vegetable. For example, a green banana has a very high content of RS, which is lowered during ripening to almost zero in a fully ripe banana. As a consequence, the amount of RS in a starch-based food may range from a few percent to as much as $40 \%$ depending on the native source and/or the way of meal preparation (Champ et al. 2003). Analysis of total starch less RS obtained by approved methods makes possible estimation of the available starch fraction. There are also several enzymic procedures available simulating the digestion in the gastrointestinal tract and making it possible to analyse the available and RS content of foods (Englyst et al. 1996; 1998). Therefore, we can conclude that measuring available $\mathrm{CHO}$ is no longer a problem for most common foods.

Since existing GI values are mostly based on available $\mathrm{CHO}$ being defined as total $\mathrm{CHO}$ minus dietary fibre, it is possible that existing GI values are based on an overestimate of the amount of available $\mathrm{CHO}$ in foods, and, thus, portion sizes which contain less than $50 \mathrm{~g}$ available CHO. This, in turn, raises the possibility that the reduced glycaemic responses of low-GI foods may be due entirely to $\mathrm{CHO}$ malabsorption. However, this does not appear to be the case. The extent to which $\mathrm{CHO}$ malabsorption accounts for reduced glycaemic responses will be discussed in detail below.

A second problem with the classical GI approach has been suggested to be the fact that it does not actually indicate the blood glucose response elicited by a food, which depends also upon the amount of CHO it contains (Monro, 2003). For example, when a food or meal is formulated to lead to a net decrease in glycaemic $\mathrm{CHO}$ by increasing protein and dietary fibre content, for instance, the reduced glycaemic potency that will be achieved cannot be accurately reflected in GI. This may disadvantage consumers. Thus it also depends on the amounts and types of fat, protein, fibre and other compounds and their interactions. Accordingly it has been suggested that the classical use of GI is difficult to understand, and that it would be easier to understand and apply on a whole-food basis, as a food effect, including all its constituents. (Monro, 2003). In principle this would also allow glycaemia to be reduced by replacing starch and sugars with indigestible $\mathrm{CHO}$ such as RS and sugar alcohols. Thus the concept of a food-based GI differs from the classical concept of GI based on available CHO. The classical GI concept implies that the diet is high in available $\mathrm{CHO}$, and aims to provide a means of controlling glycaemic responses without reducing available $\mathrm{CHO}$ intake. By contrast, the concept of a food-based glycaemic response implies that it is useful to control the magnitude of glycaemic responses by any means. All mechanisms by which glycaemia may be reduced (such as adding fat, or protein, or replacing available $\mathrm{CHO}$ with sugar alcohols, $\mathrm{RS}$, fat or protein) are assumed to have an equivalent impact on health. Yet it is difficult to prove that these concepts differ because there are no long-term studies comparing the effects of high-available CHO low-GI diets with diets in which available $\mathrm{CHO}$ was replaced with unavailable $\mathrm{CHO}$. However, it has been shown that short- term metabolic effects of reducing available $\mathrm{CHO}$ intake are different from those of slowing the rate of $\mathrm{CHO}$ absorption. This will be discussed later (p. 153) under the heading of second-meal effects.

In order to address the issue of whether a GI value should be based explicitly on available $\mathrm{CHO}$, we need to ask also to what extent the low glycaemic responses elicited by low-GI foods (based on available $\mathrm{CHO}$ ) are due to $\mathrm{CHO}$ malabsorption. If low glycaemic responses occur due to CHO malabsorption, then there would be no value in retaining the concept that the GI should be based on available CHO. However, this seems not to be the case. Although low-GI foods tend to be associated with a decreased amount of $\mathrm{CHO}$ absorbed (i.e. the amount of available $\mathrm{CHO}$ they contain has been overestimated), this only accounts for maximally $15 \%$ of the blood glucoselowering effect. In addition, the effects of a low-GI food, lentils, on the second-meal glycaemic response is the opposite to that seen with a reduced amount of $\mathrm{CHO}$ absorption, but the same as that seen by slowing $\mathrm{CHO}$ absorption (Jenkins et al. 1990) (see also second-meal effects later; p. 153).

Amount of carbohydrate absorbed. Wolever et al. (1986a) compared the amount of $\mathrm{CHO}$ malabsorbed from wholewheat bread and lentils using a breath hydrogen method and comparing the obtained data with those of directly measured contents in ileal effluent from individuals with an ileostomy. Both methods indicated that about $10 \%$ of the 'available' CHO in bread and about $18 \%$ in lentils was malabsorbed. Thus, portions of bread and lentils containing $50 \mathrm{~g}$ 'available' CHO (defined as total CHO minus dietary fibre) actually contained about $45 \mathrm{~g}$ and $41 \mathrm{~g}$, respectively, of the truly measured absorbed CHO. This difference in absorbed $\mathrm{CHO}$ would account for about a $9 \%$ difference in glycaemic response $(100 \times(45-41) / 45=8.9 \%)$. In fact, however, the glycaemic response elicited by lentils was $75 \%$ less than that of bread (Wolever et al. 1986a). Thus, malabsorption only accounted for about $12 \%$ of the reduction in glycaemic response $(100 \times 9 / 75=12 \%)$. Fig. 6 shows the relationship between GI and percentage $\mathrm{CHO}$ malabsorbed for twenty foods as directly measured in a subject with an ileostomy. The dotted line indicates the magnitude of reduction in glycaemic response which would be expected based on the reduced amount of $\mathrm{CHO}$ absorbed. Even at high levels of $\mathrm{CHO}$ malabsorption seen with legumes, the reduction in $\mathrm{CHO}$ malabsorption accounts for $<20 \%$ of the reduced glycaemic response. It is therefore believed that the major determinant of the low GI values of starchy foods in this study is a reduced rate of $\mathrm{CHO}$ absorption. Of course other mechanisms are possible, but it is true that slowing the rate of absorption of $\mathrm{CHO}$, for example by sipping glucose slowly over $3 \mathrm{~h}$, reduces glucose and insulin responses (Jenkins et al. 1990).

If, as suggested by Fig. 6, not all of the 'available' $\mathrm{CHO}$ in foods is actually absorbed, the question is raised as to how much GI values are underestimated because the portion sizes used contained less than $50 \mathrm{~g}$ available $\mathrm{CHO}$. This question has been addressed by determining the glycaemic responses of starchy foods containing high amounts of intrinsic RS (15 or $35 \%$ on total starch basis) using two different portion 


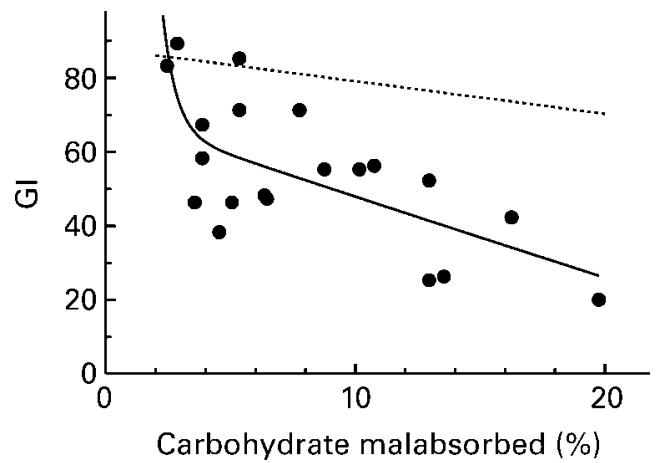

Fig. 6. Relationship between the extent of available carbohydrate absorption (measured in a subject with an ileostomy) and food glycaemic index (Gl) (Gl of glucose $=100$ ) for twenty starchy carbohydrate foods. (-), Fitted regression using two-phase exponential decay model; (----), theoretical effect on GI if the reduction in glycaemic response was exactly proportional to the reduction in the amount of carbohydrate absorbed.

sizes, one matching for total starch (or available $\mathrm{CHO}$ defined as total $\mathrm{CHO}$ minus dietary fibre), and a larger portion in which the RS was excluded from available $\mathrm{CHO}$. In the case of high-amylose maize bread, the glycaemic response elicited by the $45 \mathrm{~g}$ total starch portion, $49 \mathrm{mmol} \times \mathrm{min} / \mathrm{l}$, was identical to the response after a $55 \%$ larger portion size to account for the $35 \% \mathrm{RS}, 49 \mathrm{mmol} \times \mathrm{min} / \mathrm{l}$ (Granfeldt et al. $1995 a$ ). In the case of barley, an $18 \%$ increase in portion size resulted in a non-significant $13 \%$ increase in GI from 39 to 44 (glucose $=100$; Wolever et al. 2003). The reason for this is probably that the food factors responsible for the intrinsic RS formation also reduce the in vivo availability of the bulk of starch. In any case it is advised to estimate available and indigestible $\mathrm{CHO}$ using validated methods and correct for the indigestible part.

Glycaemic response as a function of the digestibility of available carbohydrate. In several comparative studies, the glycaemic impact of $\mathrm{CHO}$ foods has been related to the rate of digestion of available CHO. Englyst et al. (2003) correlated twenty-three cereal-based starchy foods for their GI in vivo and their rate of $\mathrm{CHO}$ digestion in vitro (as assessed by the content in rapidly available glucose). Foods were ingested on a $50 \pm 2 \mathrm{~g}$ available $\mathrm{CHO}$ basis. According to the results of analytical measurement of NSP and RS contents the twenty-three foods had very similar content in non-available CHO. However, the GI was highly variable between the different foods studied but was significantly related to the in vitro rate of digestion (rapidly available glucose content). Accordingly, GI was more explained by the rate of digestion of the available $\mathrm{CHO}$ fraction than by the content in non-available $\mathrm{CHO}$ (dietary fibre and RS).

Second-meal effects. To see if the acute metabolic effects of a low-GI food, lentils, was due to a reduced rate or a reduced amount of available $\mathrm{CHO}$ absorption, Jenkins et al. (1982) studied the effects of different breakfast test meal on the glycaemic response after a standard lunch. Subjects consumed four different breakfast meals, followed $4 \mathrm{~h}$ later by a standard lunch. The two basic breakfast meals were matched for available CHO (127-128 g), dietary fibre $(26-29 \mathrm{~g})$, protein $(57 \mathrm{~g})$ and fat $(13-18 \mathrm{~g})$ and consisted of lentils, butter and tomato, or wholemeal bread, cheese and tomatoes. The breakfasts were consumed over a period of 15-20 min. Two further breakfasts were taken; one, representing reduced $\mathrm{CHO}$ intake, contained only onequarter of the wholemeal bread but was identical in all other respects. The other, representing slow $\mathrm{CHO}$ absorption, contained the full amount of bread, cheese and tomato but eaten in small divided portions over $4 \mathrm{~h}$. The glycaemic response elicited by lentils and the continuous and the quarter bread meals were significantly less than that of the control bread breakfast (Fig. 7). However, the pattern of blood glucose response after lentils (Fig. 8) was followed much more closely by the continuous meal than by the quarter bread meal (Fig. 9). The second-meal response refers to the glycaemic response elicited by the standard lunch meal consumed $4 \mathrm{~h}$ after breakfast. The second-meal response after lentils was $38 \%$ less than that after the control bread breakfast (Fig. 7). The second-meal response tended to be less than control after the continuous bread breakfast but was significantly increased after the quarter bread breakfast (Fig. 7). These results suggest that the acute metabolic effects of slowing $\mathrm{CHO}$ absorption differ from those of reducing the amount of $\mathrm{CHO}$ absorbed, and that the metabolic effect of lentils is not due to $\mathrm{CHO}$ malabsorption. Similar conclusions were drawn from second-meal experiments done by Liljeberg et al. (1999).

These data suggest that the concept of GI based on $50 \mathrm{~g}$ available $\mathrm{CHO}$ differs from the concept of the GL or GGE based on glycaemic response as a food effect and it is therefore essential to distinguish between these measures.

Other proposed methods of classifying the glycaemic impact of foods. One method is an index based on total CHO. A relative glycaemic effect (RGE) could be determined by

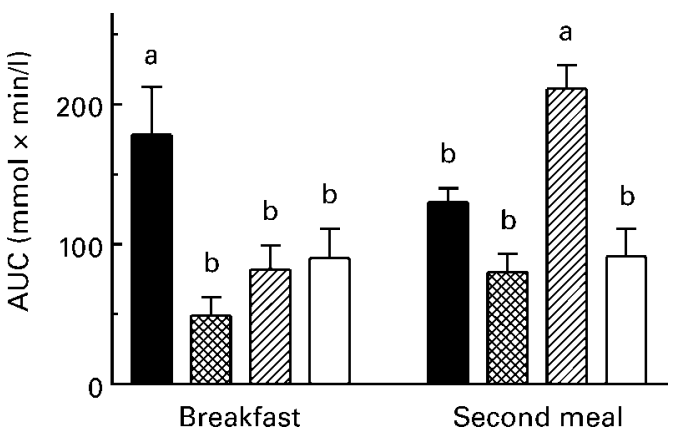

Fig. 7. Incremental areas under the blood glucose response curve (AUC) of normal subjects after breakfast and lunch test meals. Values are means and SEM. Breakfast consisted of test meals containing wholemeal bread $(\boldsymbol{\square})$ or lentils ( $($ ) , one-quarter the amount of bread (四), or the bread breakfast consumed over $4 \mathrm{~h}(\square)$. The second meal was the same on each occasion and was consumed $4 \mathrm{~h}$ after the start of breakfast. a,b Mean values within each meal with different superscript letters differ significantly $(P<0.05)$ (data from Jenkins et al. 1982). 


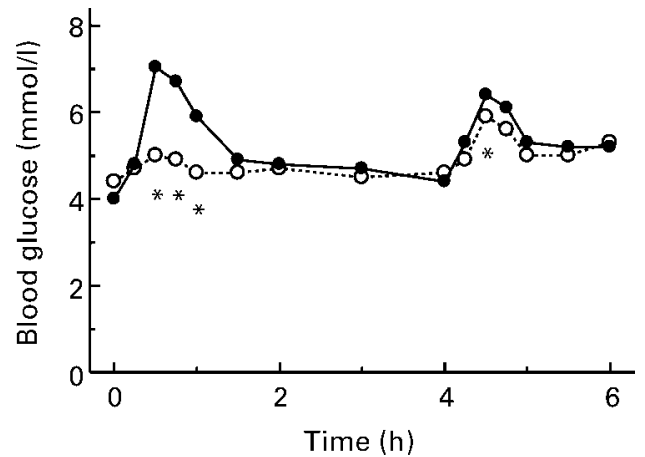

Fig. 8. Mean blood glucose concentrations of normal subjects after breakfast and lunch test meals. Breakfast consisted of test meals containing equal amounts of 'available' carbohydrate from wholemeal bread $(-\bullet-)$ or lentils $(\cdots \circ \ldots)$. The second meal was the same on both occasions and was consumed $4 \mathrm{~h}$ after the start of breakfast. * Mean values are significantly different from those for bread $(P<0.05)$ (data from Jenkins et al. 1982).

measuring the glycaemic responses elicited by amounts of foods containing $50 \mathrm{~g}$ total $\mathrm{CHO}$, expressed relative to $50 \mathrm{~g}$ glucose; that is, using a total $\mathrm{CHO}$ basis.

There seem to us several reasons why it is necessary to distinguish between GI, based on available $\mathrm{CHO}$, and RGE based on total $\mathrm{CHO}$. First, unavailable $\mathrm{CHO}$ may or may not influence the glycaemic impact of digestible $\mathrm{CHO}$ consumed at the same time with them. Not controlling for the amount of available $\mathrm{CHO}$ would mean that valid conclusions as to whether reduced glycaemic responses were due to a reduced amount of available $\mathrm{CHO}$ or to some other effect cannot be drawn. Second, as described elsewhere in the present paper, the metabolic effects of consuming a certain amount of $\mathrm{CHO}$ while slowing its absorption are different from those of reducing the amount of $\mathrm{CHO}$ absorbed. Regarding the latter, most of the studies in this area compare the effects of exchanging sucrose or

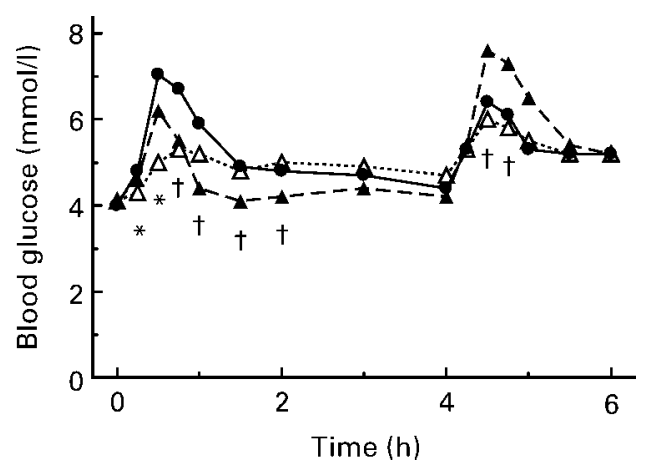

Fig. 9. Mean blood glucose concentrations of normal subjects after breakfast and lunch test meals. Breakfast consisted of test meals containing wholemeal bread $(-\bullet-)$ consumed over $15-20 \mathrm{~min}$, onequarter the amount of bread $(-\boldsymbol{\Delta}-)$, or the full bread breakfast consumed over $4 \mathrm{~h}(-\triangle-)$. The second meal was the same on each occasion and was consumed $4 \mathrm{~h}$ after the start of breakfast. ${ }^{*}$ Mean values for slow bread are significantly different from those for control bread $(P<0.05)$. † Mean values for one-quarter bread are significantly different from those for control bread $(P<0.05)$ (data from Jenkins et al. 1982). dextrins with fructo-oligosaccharides or inulin (Williams \& Jackson, 2002). Effects that are seen in these cases may, along with a reduction of the amount of glycaemic $\mathrm{CHO}$ ingested, be due to the production of short-chain fatty acids during colonic fermentation (Brighenti et al. 1999).

Another method is based upon GL or GGE. The term GL was first proposed by Salmeron et al. (1997a) and was defined as the quantity GI $\times \mathrm{g}$, where GI is the food GI and $\mathrm{g}$ is the weight of $\mathrm{CHO}$ the food portion contains. Thus, a particular GL may be achieved either from low-GI foods, or from high-GI foods at a lower available CHO intake. The ability of GL to predict glycaemic responses has been tested (Brand-Miller et al. 2003b), and GL values for a large number of foods have been published (Foster-Powell et al. 2002). It has been assumed that if more servings of food are consumed, GL values are additive without energy adjustment (Brand-Miller et al. 2003b); however, whether this is so is not clear since the original rationale for the use of GL was based on epidemiological studies in which GL was adjusted for energy intake.

Monro introduced the term GGE (Monro, 1990a, b, 2002; Monro \& Williams, 2000) which is defined as: 'the weight of glucose equivalent in its effect to a given weight of food'. GGE can be calculated using existing GI tables as follows: $\mathrm{GGE}=$ food weight $(\mathrm{g}) \times \% \mathrm{CHOAVL} \times\left(\mathrm{GI}_{\text {food }} / \mathrm{GI}_{\text {glucose }}\right)$, where \%CHOAVL is the amount of available $\mathrm{CHO}$ contained in $100 \mathrm{~g}$ food, $\mathrm{GI}_{\text {food }}$ is the GI value of the food and $\mathrm{GI}_{\text {glucose }}$ is the GI of glucose $(=100)$. Thus, GGE is equivalent to GL. It has been suggested that GGE is an accurate predictor of glycaemic responses (Liu et al. 2003), but the validity of this conclusion has been questioned (Wolever, 2004a).

In general the utility of the above-mentioned methods of classifying glycaemic responses, i.e. RGE, GL and GGE, remains to be better established. Issues which need to be addressed include: what is the reproducibility of the values; are the values the same in different subjects; are the values affected by glucose intolerance or insulin resistance; do they hold in mixed meals; does altering dietary intake based on them result in long-term improvement in glycaemic control, blood lipids, body weight, or other health-related indicators?

In general the validity of the above estimates of GI of available $\mathrm{CHO}$ and glycaemic impact remains to be better established. In this respect it should also be noted that a value of GI might not be appropriate when the intake of fat is high (see Flint et al. 2004).

Recommendation. It is recommended that the measurement of GI of test foods is based on comparing equivalent amounts of available $\mathrm{CHO}$ (for further explanation on the definition of available $\mathrm{CHO}$, see later; p. 156). For clarity and precision in terminology, it is recommended that the term 'GI' be restricted to tests of foods based on available $\mathrm{CHO}$, and that different terms, such as RGE, GL or GGE, be used to classify the glycaemic impact of foods based on total $\mathrm{CHO}$ or serving size.

\section{What should be the carbohydrate dose?}

Scientific background. Generally, most of the tested foods contain significant amount of available $\mathrm{CHO}$ (as g eaten in a 
serving, or as $\mathrm{g} / 100 \mathrm{~g}$ food). A $50 \mathrm{~g}$ available $\mathrm{CHO}$ load has been initially proposed as a reference amount for GI testing. However, in the case of foods with low to moderate $\mathrm{CHO}$ density, this may lead to large volumes having to be ingested. Increasing the intake quantity of $\mathrm{CHO}$ increases incremental AUC glucose response in a dose-response manner in healthy subjects (Wolever \& Bolognesi, 1996a; Lee \& Wolever, 1998). However, the dose-response curve is curvilinear and shows a trend to plateau at intakes greater than $50 \mathrm{~g} \mathrm{CHO}$. Small intakes of high-GI foods also elicit a glucose response, whereas glucose only slightly increases after the consumption of a $25 \mathrm{~g} \mathrm{CHO}$ load of low-GI foods. In addition, after an intake of less than $10 \mathrm{~g} \mathrm{CHO}$, a significant change in blood glucose may not be detected. Therefore, a range of 25 to $50 \mathrm{~g}$ available $\mathrm{CHO}$ appears to be most appropriate for GI testing experiments, with $50 \mathrm{~g}$ as the preferred target dose. Less than $25 \mathrm{~g}$ available $\mathrm{CHO}$ (but higher than $10 \mathrm{~g}$ ) may be considered for foods with very low available $\mathrm{CHO}$ content, but can at present not be recommended due to lack of data. Accordingly, this requires further research. Finally, when the reference food is glucose, the nature of the glucose source has to be taken into account. In the case of monohydrated glucose, a correction factor, taking into account the water linked to the glucose, has to be used to calculate the quantity of $\mathrm{CHO}$ provided from glucose. Indeed, $1.1 \mathrm{~g}$ monohydrated glucose provides $1.0 \mathrm{~g}$ glucose.

Recommendation. We recommend testing $50 \mathrm{~g}$ available $\mathrm{CHO}$ loads. In the case of foods with low to moderate $\mathrm{CHO}$ density, it is justified to lower the CHO load to $25 \mathrm{~g}$ to avoid an unrealistically large meal size and to adjust to $25 \mathrm{~g} \mathrm{CHO}$ the referent food portion.

\section{How should carbohydrates be analysed and calculated?}

Scientific background. According to the FAO definition currently used in many countries, 'total carbohydrate less dietary fibre' is defined as available CHO. At present we know that this may often be incorrect, since this definition does not account for indigestible $\mathrm{CHO}$ that from a physiological point are dietary fibres (Champ et al. 2003) but are not measured using the classical dietary fibre analytical method. Some examples of such $\mathrm{CHO}$ are the fructans inulin and fructo-oligosaccharides and type 3 RS. Accordingly the available $\mathrm{CHO}$ should, as far as possible, be analysed with approved specific analytical methods. Simple and appropriate enzymic procedures are available for analysis of the main potentially available $\mathrm{CHO}$ in foods i.e. available starch, lactose, sucrose, glucose and fructose (maltodextrins, maltose). For practical purposes, these methods can be expected to give a reasonably good estimate of the available $\mathrm{CHO}$ load in foods with only intrinsic $\mathrm{CHO}$. In the case of starchy foods, the bioavailable starch fraction as well as RS can be analysed with specific analytical procedures (McCleary \& Monaghan, 2002; for a review, see Champ et al. 2003). When some CHO components such as RS or sugar alcohols may occur in non-transformed or manufactured foodstuffs, the evaluation of these components, using accurate procedures, is recommended.

Fig. 10 shows possible ways to obtain the analytical contents in $\mathrm{CHO}$ components and to calculate the load of a defined amount of available $\mathrm{CHO}$ to be tested. When required, a conversion factor is recommended to adjust $\mathrm{CHO}$ that are being tested (available starch, disaccharides, monosaccharides) to a comparable monosaccharide level. 'Indeed $1 \mathrm{~g}$ available starch delivers $1 \cdot 1 \mathrm{~g}$ glucose units during digestion because of hydration during hydrolysis process, whereas the conversion factor to be used for available disaccharides is 1.05 .'

Recommendation. It is recommended that the main potentially available $\mathrm{CHO}$ in foods, i.e. available starch, lactose, sucrose, glucose and fructose, are analysed with accurate analytical methods. For starch-containing foods, analytical procedures are recommended that allow separate determination of the available starch and the RS.

\section{When should the test take place?}

Scientific background. To be comparable with other foods in the GI tables, the test should be taken at breakfast time in the morning. This fasted condition is most stable concerning possible intra-individual differences due to time of the day and meal influences. There is evidence that the glycaemic response data obtained from a test at lunchtime, after a standard breakfast, differ significantly from those obtained after an overnight fast. For example, RGR of two breakfast cereals were studied after a $10-14 \mathrm{~h}$ overnight fast or at lunchtime after a standard breakfast. It was observed that the difference in glycaemic response between the cereals when tested in the morning was significantly greater than that observed at lunchtime (Wolever \& Bolognesi, 1996c).

Recommendation. The test should preferably take place before 10.00 hours in the morning, after a $10-14 \mathrm{~h}$ overnight fast.

\section{Subject preparation}

What should be the preparation (instructions to subjects) before the measurement?

Scientific background. Many factors modulate the response to a test meal in any one subject and differences in these factors between eating occasions would be expected to be a potential cause of inaccuracies in GI, GL, GGE, etc. It has long been known that the $\mathrm{CHO}$ content of the diet for the few days before an oral glucose tolerance test markedly affects the result, with poorer glucose tolerance being observed after a low-CHO diet (Hales \& Randle, 1963). Acute physical exercise can increase muscle glucose uptake on the following day (Malkova et al. 2000), and improve insulin sensitivity for $48 \mathrm{~h}$ (Mikines et al. 1988). This usually results in lower plasma insulin concentrations in response to nutrient ingestion (Tsetsonis \& Hardman, 1996; Tsetsonis et al. 1997), although generally there is no effect on systemic fasting plasma glucose concentrations (Tsetsonis \& Hardman, 1996; Tsetsonis et al. 1997; Malkova et al. 2000). Folch et al. (2003) recently studied the effect of a large starch meal at rest and after exercise in men and women and observed that the contribution of substrate oxidation to energy expenditure as well as fat and glycogen balance and the effect of previous exercise were similar in men and 


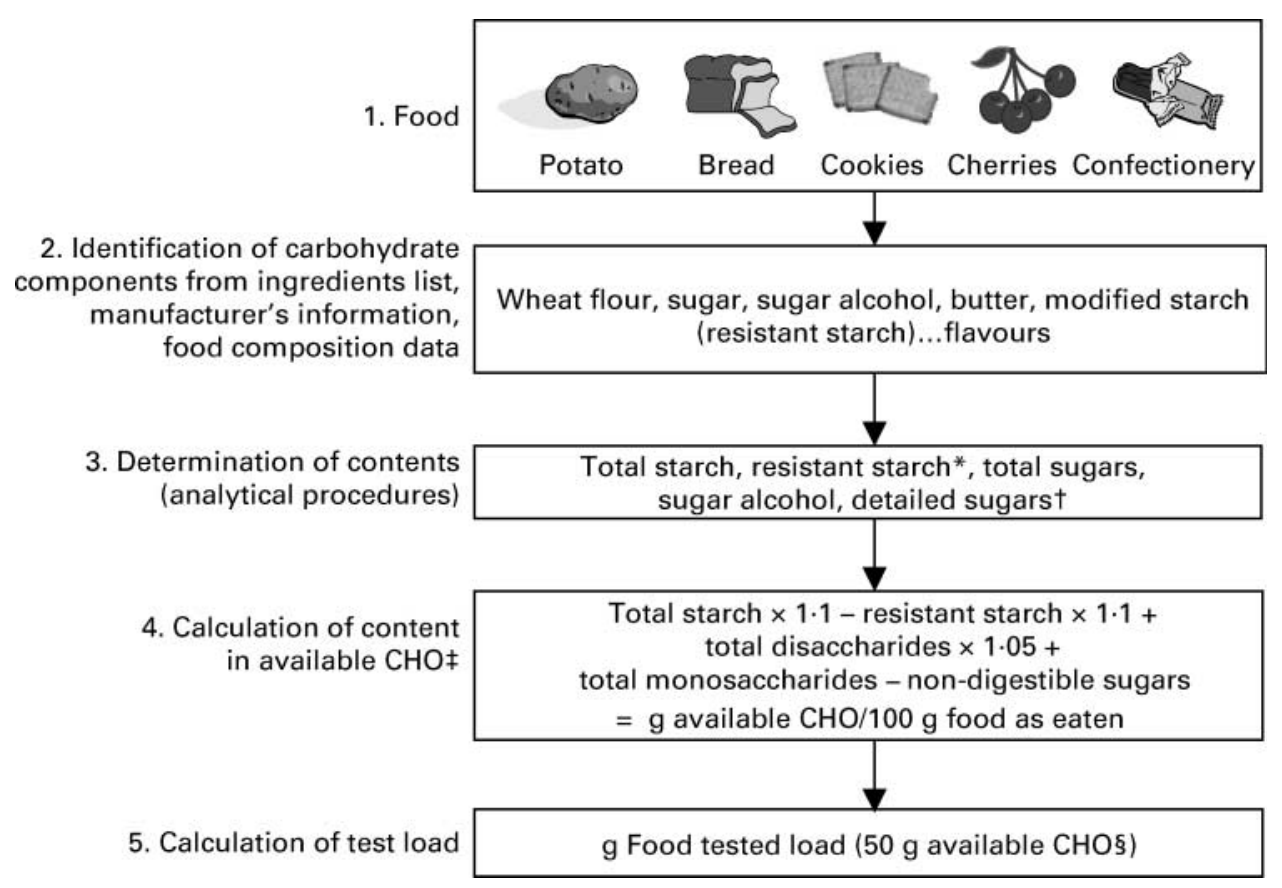

Fig. 10. Principles of analysis and calculation of available carbohydrate $(\mathrm{CHO})$ in test foods. ${ }^{*}$ This analysis is optional, and depends on the estimated content (step 2). † This analysis is recommended when possible. Results allow to calculate the total sugars content. A correction factor can also be applied to disaccharides $(\times 1.05)$ to convert into monosaccharide equivalents, depending on the method used. $\ddagger$ Correction factor of 1.1 is to be applied to convert starch content into monosaccharides (glucose) equivalents, and a correction factor of 1.05 is to be applied to convert disaccharides content into monosaccharides (glucose) equivalent (depending on the method used). § This last step of calculation is to be adapted according to the decided available $\mathrm{CHO}$ served load.

women. Post-exercise, however, postprandial plasma glucose levels differed significantly from rest.

Alcohol consumption may have profound effects on glucose homeostasis (Shelmet et al. 1988; Siler et al. 1998), especially in the fasting state, although the effects of alcohol consumption on metabolism the following day do not appear to have been tested. Cigarette smoking is another potential confounder since it may cause acute insulin resistance (Attvall et al. 1993; Frati et al. 1996). Intake of dietary RS on the day before a meal challenge may improve glucose tolerance (Robertson et al. 2002). Even the composition of the evening meal the day before a test may affect the result. Meals rich in either $\mathrm{CHO}$ or fat on the evening before a meal-challenge test have significant effects the following day: fat tolerance is poorer following a $\mathrm{CHO}-$ rich evening meal; glucose tolerance is poorer following a fat-rich (low-CHO) evening meal (Robertson et al. 2002). However, the effect of evening meal macronutrient composition on fat tolerance is much more marked than the effect on glucose tolerance (Robertson et al. 2002). The GI of the evening meal may also exert an effect independent of macronutrient composition. Evening meals of low GI produce better glucose tolerance the following morning compared with evening meals of high GI (Wolever et al. 1988b; Thorburn et al. 1993). This effect may be due to colonic fermentation, since it is seen with barley but not with spaghetti with an identical GI (Granfeldt et al. 2005).

The exact length of the overnight fast may also be important: the steady state often supposed to exist after overnight fast is, in fact, a time of significant change in terms of falling plasma insulin concentrations and increasing lipolysis (Klein et al. 1993; Samra et al. 1996).

In view of all these factors, it might well be supposed that strict standardisation of diet and activity for $24 \mathrm{~h}$ before the measurement of GI would improve the reproducibility of results. In practice, however, such standardisation considerably increases the burden on participants and investigators, and it is important, therefore, to ask whether the supposed benefits are seen in reality. This question was studied by Campbell et al. (2003). They compared tests in which exercise and evening meal on the day before the test, and the length of overnight fast, were strictly controlled, with 'uncontrolled' tests. No smoking was allowed on the morning of the test on either occasion. In contrast to expectations, the variability of results was no greater in the 'uncontrolled' tests and in fact tended to be lower. There was no effect on mean values of glycaemic response. Participants who were smokers (three out of thirteen) reported 'craving' during the controlled tests, but nevertheless returned similar values for glycaemic response and variability under the two conditions. Vigorous physical activity on the day before the 'uncontrolled' tests did not produce a significant effect, although there was a tendency to lower blood glucose concentrations at $90 \mathrm{~min}$. Whilst the effects of many of these measures have been shown under other laboratory conditions, it appears that they are not of sufficient significance to warrant stricter controls when applied to GI testing. 
Recommendation. We recommend that in practice there is no need for rigorous control of exercise, smoking or diet on the day before the test. Unusual vigorous activity should be avoided, however. Subjects should eat their normal diet on the previous day. We recommend that the evening before a test each subject should consume a meal of choice and repeat that meal before each test. Smoking should not be allowed on the day of the test. We emphasise that our recommendation applies to the measurement of glycaemic responses. Other metabolic investigations, especially of fat metabolism, may be much more susceptible to the effects of prior exercise and diet.

\section{Re-utilisation of control test results}

Can the results from the reference glucose tests from a selected group of subjects from one study be used for subsequent studies?

Scientific background. Using reference values that have been obtained in one study as reference values in another subsequent study would only be acceptable by respecting the following two conditions:

(1) Between two studies, the subjects must not undergo physiological changes (for example, significant weight change, starting medical treatment, changes in physical activity) leading to important changes in their fasting blood glucose or in their glycaemic response to foods;

(2) The position of the glucose tests in the studies is relevant (see question 'how many times should the test be reproduced for the standard and test foods'; p. 148). If a glucose test is always done at the beginning and at the end of the study, the last glucose test of the first study can be used as the first glucose test of the second study. However, since no data are available on the impact of time on changes in response to the reference food, we recommend limiting the time between tests to a maximum of 2-3 months. Applying reference data from one study to data collected in another is generally considered poor scientific practice, although it may yield reasonable results. Although practiced often it is not recommended to do so.

Recommendation. In case that the same subjects are tested in subsequent trials with short intervals, test data of the reference food in a particular group of subjects can be used for different studies in the same subjects, if the test of the reference food occurred within 3 months. However, at least one new test of the reference food should be done in every study, and, in each study, one test of the reference food should be done at least every 3 months, or for every six foods tested by the subject, whichever is more frequent.

\section{How should the randomisation be done?}

Scientific background. Randomisation in clinical trials is necessary to eliminate bias in treatment assignment, facilitate blinding of the identity of the treatments from the investigators and to permit the use of probability theory to determine the statistical significance of the results
(Schulz \& Grimes, 2002a). As important as the treatment assignment is allocation concealment, to prevent the investigators from deciphering assignments, which subverts the purpose of randomisation (Schulz \& Grimes, 2002a). These considerations apply to parallel-design clinical trials of drugs, but are difficult or impossible to apply to studies in which the GI of foods is determined. One reason for this is that GI trials are cross-over studies in which all subjects undergo all treatments. In addition, it is usually impossible to blind either the subjects or the investigator from the treatments being undertaken, and efforts to do so may change the nature of the food tested and hence alter the results. Bias in GI trials is possible if either subjects or investigators try to modify the results of a test by changing their behaviour based on knowledge of the upcoming test, or change the order of the treatments based on their behaviour. Creating a list of the order in which tests will be done, and not telling the subject about which food product will be received before it is presented as the test meal may help minimise these problems but is insufficient to prevent bias from occurring. The advantages of using true randomisation to allocate the order of test of the foods, as opposed to nonrandomised methods of mixing up the order of treatments, is not clear. In addition to minimising bias, randomisation of the treatments in GI studies is desirable to control for systematic 'order' effects, and for non-systematic random events, both of which may influence the results. It is possible to achieve better balance among the possible orderings of test foods in time by using an adaptive randomisation procedure or minimisation. In this approach, orderings that include foods that have already been assigned to subjects disproportionately early in the order will become less likely to be assigned than orderings in which these foods are scheduled later. However, because of the additional complexity this creates in the study design and analysis, and because practical considerations as noted later may be of overriding concern, we do not feel there is a need for adaptive randomisation and opt instead to include order effects as a covariate in the analysis.

Examples of systematic order effects might be related to stress or seasonal effects. Subjects who are new to the testing procedures may experience more anxiety during the first few tests they perform than they do after becoming used to the procedures. Anxiety may influence glycaemic responses via delayed gastric emptying or insulin antagonistic effects of stress hormones. If subjects are studied over a period of several months, seasonal changes may influence the diet and activity patterns of the individual, which, in turn, may affect glycaemic responses. Examples of random effects might be a sudden hot spell, or a breakdown in the air-conditioning system in the laboratory, which affects the performance of the glucose analysers. Factors that influence how treatments are randomised include the nature and number of foods tested, the number of times the reference food is repeated and the number of subjects being studied. Consideration of how the number of subjects influences the methods of randomisation and concealment is critical for parallel studies, but not quite so important for cross-over studies. The main issue is that, with small numbers of subjects, simple randomisation procedures commonly result in unequal group sizes. For example, a sample size of ten, 
over $33 \%$ of sequences generated with simple randomisation, would yield a ratio imbalance of 3:7 or worse (for a sample size of twenty, the probability is nearly $12 \%$ ). Various strategies for randomising in blocks can prevent unequal group sizes, though it has been argued that some inequality in group size is desirable to enhance concealment (Schultz \& Grimes, 2002b). Complete randomisation of all the test reference foods could result in all the reference food tests being conducted first, or last or all together in the middle. If a large number of foods were being tested, the study may last for 3-4 months, and the grouping together of the reference food tests would make it difficult to detect any systematic order effects. To determine whether systematic order effects are present, the three trials of the reference food could be conducted first, last and in the middle of the sequence of test foods. To minimise bias due to random events, it is most desirable to randomise the order of the foods tested. However, in certain situations it is not possible or desired to completely randomise all the food tests; for example, the desire to obtain results for some foods first, or the testing of foods with a short shelf-life (for example, fresh potatoes). Randomisation in blocks is acceptable, but doing reference food tests after each block test may be considered to control for order effects. True randomisation of the order of testing of the foods would be ideal, but is not commonly practiced, and is not considered necessary due to the absence of data about the magnitude of bias introduced by non-randomised allocation of the order of testing. More sophisticated experimental designs, such as partial latin square, where each subject ingests several but not all foods, may allow more foods to be tested in a single experiment in less time and with less burden on the subjects. Thus far, data using such approaches for GI testing are lacking, thus not allowing for making recommendations.

Recommendation. It is recommended that foods for testing be randomised in blocks of up to six foods with a trial of the reference food being done before and after each block. The reference food trial performed after the first block of test foods can be used as the first reference food trial in the next block of test foods. Randomisation is not the only approach to assign tests and subjects.

\section{Should we include as many males as females?}

No differences have been observed in glycaemic response between males and females (Wolever et al. 2002). Accordingly, there are no grounds to avoid the common practice of inclusion of both sexes in a study.

\section{How many foods in one batch of tests?}

(a) Can we test as many foods as we want in one test?

(b) Is there a maximal number of test foods that can be compared with the mean of two to three reference foods?

Scientific background. Studies that have been done in the past have evaluated as much as up to twelve foods in one GI experiment, along with three times the control test. The reference test has been repeated every $6-8$ weeks. The total test duration should not exceed 4 months, to avoid possible seasonal variations in GI. An ideal set-up may be to test three test foods, along with three control-reference trials, in a period of 2 weeks, allowing to test on Monday, Wednesday and Friday.

Recommendation. The total test duration should not exceed 4 months. With multiple food testing a reference test should be done at the beginning and a repetition should take place after every 6-8 weeks.

\section{How should blood be sampled?}

Scientific background. Arterial blood is delivered from the heart to the tissues of the body. The concentration of glucose in arterial blood is therefore in principle the measurement of interest because this is the concentration to which the tissues are exposed. However, sampling of arterial blood is an invasive procedure that carries some risk and is unlikely to be applied to the measurement of GI. Alternatives are: (i) capillary blood, which approximates arterial blood in composition - this necessitates puncture of the skin (usually on the finger or earlobe); (ii) venous blood taken from a cannula in a vein, usually on the forearm or in the antecubital fossa; (iii) 'arterialised venous' blood, taken from a cannula in a vein draining the hand, the hand then being warmed to open arterio-venous anastomoses (so that substrate concentrations resemble arterial blood). Because the tissues consume glucose, the concentration of glucose in a peripheral vein will be lower than that in an artery. The magnitude of this arterio-venous difference may be considerable, especially after glucose ingestion when insulin stimulates glucose uptake. In one study, the glucose concentration in blood taken from an antecubital vein was $4 \mathrm{mmol} / \mathrm{l}$ lower than that in arterialised venous blood at $60 \mathrm{~min}$ after ingestion of glucose (Frayn et al. 1989). Furthermore, this difference is not consistent; ambient temperature, for instance, affects the rate of blood flow through the forearm and has a marked effect on venous blood glucose concentrations (Frayn et al. 1989). Therefore, venous glucose measurement might be expected to be more variable than capillary. This has been confirmed directly in the interlaboratory study of GI, in which laboratories taking venous blood returned $\mathrm{CI}$ of $>50 \%$, compared with $<30 \%$ in all laboratories using capillary blood (Wolever et al. 2002, 2004).

Direct comparisons between capillary and venous blood also bear out this difference. Capillary blood glucose concentrations were consistently greater than venous blood glucose concentrations when assessed during the measurement of GI of various products, so that AUC were 33-40\% lower for venous blood glucose (Granfeldt et al. 1995b). However, the measurements of GI were not affected as both reference and test measurements were similarly affected. Sensitivity of the measurement, however, was greater using capillary blood sampling (Granfeldt et al. 1995b). The site at which capillary blood is taken may affect the result. When glucose concentrations are rising or have just risen sharply, fingertip capillary glucose concentrations are greater than those in capillary blood from other sites including forearm, thigh and abdomen (Ellison et al. 2002; Jungheim \& 
Koschinsky, 2002; van der Valk et al. 2002), with variable differences in repeated tests on the same subject (Ellison et al. 2002); conversely, when blood glucose concentrations fall, fingertip capillary glucose concentrations are lower than those on the forearm (Jungheim \& Koschinsky, 2002). The message is that fingertip capillary sampling is preferable to other sites. Earlobe and fingertip capillary blood do not seem to have been compared directly.

Practicalities. Placement of a venous cannula requires some medical or nursing supervision; on the other hand, once in place, blood sampling is painless. Many subjects do not like repeated stabs for capillary blood; on the other hand, again, methods for sampling capillary blood are being refined and with practice the technique can be made almost painless. Placement of a cannula for sampling arterialised venous blood is made in a retrograde direction, which is slightly more difficult than normal cannulation. The hand can then be warmed in a variety of ways, although hot water is not recommended as heat transfer to the body is significant, and a box with relatively static air at $55-60^{\circ} \mathrm{C}$ works best in practice (Frayn \& Macdonald, 1992). Sampling capillary blood results in relatively smaller volumes. If it is desired to measure substances other than glucose (for example, insulin) this may be possible using micro-methods. However, if a number of hormones or metabolites are to be measured, then larger samples will be needed, and arterialised venous blood may be the method of choice (Wolever, 2004b). Measurement in whole blood is also possible. Whole-blood and plasma glucose concentrations are closely related and one can be calculated from the other if the packed cell volume is known (Dillon, 1965). Provided that either plasma or whole blood are being used consistently in any series of measurements, no bias should be caused. However, it would not be appropriate to use plasma on one occasion and whole blood on another.

Recommendation. We recommend the use of either capillary or arterialised venous blood and discourage the use of normal venous blood. Fingertip capillary blood appears to give the greatest sensitivity. We recommend the use of either capillary or arterialised venous blood and discourage the use of normal venous blood in order to improve sensitivity and to remove the potential for variations in measured GI due to fluctuations in factors such as ambient temperature. Fingertip capillary blood appears at present to give the greatest sensitivity, but with improved methods for sampling of capillary blood becoming available, more research could be conducted on alternative sites. Whole blood and plasma concentrations are closely related and one can be calculated from the other if the packed cell volume is known.

\section{Measure both glucose and insulin?}

Scientific background. A growing body of research resulting from dietary trials and large epidemiological studies indicates that diets with a high GI or high GL are associated with an increased risk of insulin resistance, dyslipidaemia, and the development of CVD and type 2 diabetic subjects (Slabber et al. 1994; Salmeron et al. 1997a,b; Frost et al. 1999). In addition, hyperinsulinaemia has also been implicated as a risk factor for the development of arteriosclerosis (Leeds, 2002), CVD (Frost et al. 1999; Leeds, 2002), diabetes (Willett et al. 2002), cancer (McKeown-Eyssen, 1994; Giovannucci, 1995) and juvenile myopia (Cordain et al. 2002).

Measurement of insulin response to foods, and the introduction of an insulinaemic index concept (Holt et al. 1997) could be of value in investigating health issues. However, more data are necessary concerning potential differences in GI and insulinaemic index between foods. Moreover, an insulin index is likely to be influenced by the pathophysiological status of the test subject (Wolever et al. 2004).

To date, most GI studies have not measured the postprandial insulinaemic responses accompanying the glycaemic responses of the test foods examined. However, for many $\mathrm{CHO}-$ rich foods and pure $\mathrm{CHO}$, there appears to be a close correlation between glycaemic and insulinaemic responses (Holt et al. 1997; Englyst et al. 2003). It should be acknowledged though that certain foods produce higher insulin responses than expected from their GI (Ostman et al. 2001). Especially, protein is known to induce a larger insulin secretion, when combined with $\mathrm{CHO}$. Thus, to obtain more data on glucose homeostasis of nutrient combinations, insulin measurement may be desirable. In case of the latter, most often venous blood will be needed to obtain blood samples that are large enough. Measurement of insulin in small capillary samples or using arterialised blood using a hand placed in a heat box is the method of choice but this needs more sophisticated equipment and experience.

Recommendation. For routine use of the GI method, glucose measurement is enough and we do not recommend to systematically measure the insulin level. When the measurement of insulin response in addition to glucose response is of interest for other reasons, or when budget limitations do not play a role, we recommend the measurement of both for completeness.

\section{Blood-sampling time schedule}

What should be the optimal blood-sampling schedule?

Scientific background. Usually blood is sampled in the fasting state and at 15, 30, 45, 60, 90 and $120 \mathrm{~min}$ after starting to eat the test meal in individuals without diabetes. And in subjects with diabetes, usually blood is obtained in the fasting state (0) and at 30,60, 90, 120, 150 and $180 \mathrm{~min}$ after starting to eat. Taking blood samples less frequently (sampling blood every $30 \mathrm{~min}$ instead of every $15 \mathrm{~min}$ ) or for less than $2 \mathrm{~h}$ in normal subjects significantly influences the mean and variation of the resulting AUC (Wolever, 2004b). The mean and variation of the resulting GI values also tend to increase as the frequency and duration of blood sampling decreases. 'In addition, reduced frequency and duration of blood sampling resulted in the development of statistically significant correlations between the mean AUC of the reference food and the mean GI of the test foods in the different subjects, a correlation which is not significant' (Wolever, 2004b). The existence of a correlation between 
AUC and GI indicates that GI is not adequately controlling for differences in glycaemic response between subjects, and hence that the GI varies in different subjects. The GI is known to be a property of the food independent of subject characteristics. Therefore, methods that result in GI values that do not control for differences in AUC between individuals cannot be considered to be valid.

Gannon \& Nuttal (1987) analysed the effect on RGR of altering the length of time over which blood samples were taken from 1 to $5 \mathrm{~h}$. RGR is defined as the net incremental glucose AUC (see Fig. 11) after a test meal expressed as a percentage of the net area after $50 \mathrm{~g}$ glucose. The results are not necessarily able to apply to the GI because RGR is based on calculating AUC using a different method than used for determining GI (incremental AUC). For legumes, the RGR markedly increased as the length of time of blood sampling increased. This is presumably because, after consuming foods such as legumes, which are slowly digested and absorbed, blood glucose concentrations tend to remain above the fasting level for several hours, in contrast to the consumption of glucose after which the blood glucose concentrations undershoot the baseline. Thus, as the time over which net AUC is calculated is extended, positive area accumulates for the legumes (i.e. net AUC becomes larger), while negative area accumulates for glucose (i.e. net AUC becomes smaller). After sucrose, milk and fructose, the RGR markedly decreased as the length of time over which blood was sampled increased, presumably because blood glucose concentrations after these test meals undershot more than after glucose. For starchy foods such as bread, oats and potato, there was only a small effect of time of blood sampling on RGR. Although an analysis to see if extending the length of blood sampling beyond $2 \mathrm{~h}$ affects the GI value has not been performed, it seems probable that there may be effects, which may vary for different types of foods.

Thus, adhering to a standardised schedule of blood sampling with respect to both frequency and length of time is likely to be important for obtaining valid and consistent GI values. Analysing more than one baseline sample may theoretically reduce the variability (more sampling) or increase variability (baseline may fall with time). In practice, analysing data from nineteen subjects showed this to have only a very small effect overall on the incremental AUC.

Recommendation. We recommend the following blood sampling schedule in subjects without diabetes: fasting $(0)$ and at $15,30,45,60,90$ and 120 min after starting to eat the test meal.

\section{Washout period between two consecutive tests}

What should be the duration of the washout period?

The food tested on a first session must not influence the glycaemic response of the subject to the food tested on the next session. Thus, making two test sessions on two successive days, or with a washout period of $1 \mathrm{~d}$, may not be enough. But it seems that a washout period of $2 \mathrm{~d}$ is enough. In fact, the impact of the food tested on the metabolism of the subject $2 \mathrm{~d}$ later, if any, is negligible. Moreover, the subject eats between the two sessions, and these meals have more effect on the next test than the portion test eaten $2 \mathrm{~d}$ before.

Recommendation. There are no data to make any recommendation at this stage. Therefore, we recommend further research addressing this issue.

\section{How should the glycaemic index be calculated?}

Which type of calculation of AUC should be applied?

Scientific background. Many methods can be used to calculate AUC (Fig. 11), and since use of the different methods can result in different GI values (Table 2), this should be standardised.

The methods mostly discussed are:

(1) Total AUC;

(2) Incremental area until first return to baseline (incremental $\mathrm{AUC}_{\text {cut }}$ ); (a)

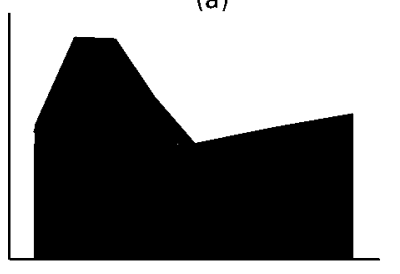

(c)

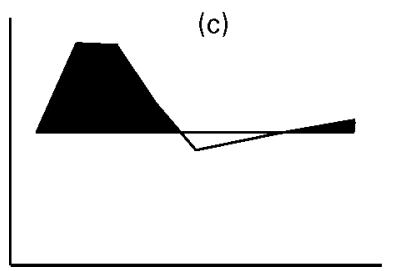

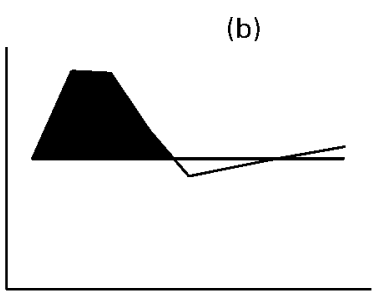

(d)

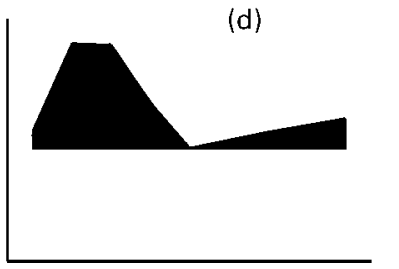

(e)

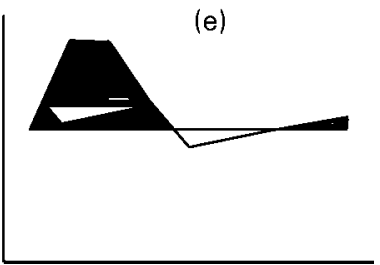

Fig. 11. Different methods to determine area under the curve (AUC). (a), Total AUC, method 1; (b), incremental $A U C_{c u t}$, method 2 ; (c), incremental AUC, method 3; (d), incremental $A \cup C_{\text {min }}$, method 4; (e), net incremental AUC, method 5. 
Table 2. Evaluation of different methods of calculating area under the curve (AUC) for determining glycaemic index (GI) values of foods*

\begin{tabular}{|c|c|c|c|c|}
\hline Method number & Mean Gl & SD of GI & Correlation† & Agreementł \\
\hline 2 (Incremental $\left.\mathrm{AUC}_{\text {cut }}\right)$ & $62 \cdot 4^{\mathrm{a}}$ & $21 \cdot 2$ & $-0.112(N S)$ & $\pm 3.3(5.1 \%)$ \\
\hline 3 (Incremental AUC) & $62 \cdot 8^{\mathrm{a}}$ & $20 \cdot 4$ & -0.139 (NS) & - \\
\hline 4 (Incremental $\left.\mathrm{AUC}_{\min }\right)$ & $57 \cdot 2^{\mathrm{b}}$ & $20 \cdot 6$ & $-0.430(P=0.003)$ & $\pm 13.0(20.7 \%)$ \\
\hline 5 (Net incremental AU'C) & $64 \cdot 3^{\mathrm{a}}$ & $24 \cdot 0$ & 0.140 (NS) & $\pm 8.9(14.2 \%)$ \\
\hline
\end{tabular}

${ }^{a, b}$ Mean GI values with unlike superscript letters differ significantly.

* Data from five foods tested in eight to ten subjects in five different centres (total of forty-seven subjects). For the methods, see Fig. 7 and Table 3.

† Correlation between mean GI value for five foods in each subject and that subject's mean AUC after oral glucose.

¥Limits of agreement according to Bland \& Altman (1986) of the twenty-five mean Gl values (five foods, five centres) for each AUC method compared with those using the recommended method (option 3). Limits of agreement are 1.96 times the SD of the difference between the GI values, i.e. the range within which $95 \%$ of the differences would be expected to lie. The value in parentheses represents the limit of agreement expressed as a percentage of the mean GI value.

(3) The area over the baseline under the curve, ignoring area beneath the curve (incremental AUC);

(4) Incremental area using the lowest blood glucose as the baseline (incremental $\mathrm{AUC}_{\min }$ );

(5) The net incremental AUC (apply trapezoid rule for all increments positive and negative) (net incremental AUC).

Method 1, total AUC, includes all the area under the blood glucose response curve down to a blood glucose concentration of 0 . Fasting glucose is independent of the food consumed. Thus variations in total AUC due to variation in fasting glucose are not due to the test meal consumed. In addition, the portion of total AUC below fasting glucose is independent of the test meal. The test meal can only affect AUC above the fasting level (unless there is an undershoot). Since the area above the fasting glucose is only a small proportion of the total AUC, total AUC is insensitive for distinguishing between foods with different glucose-raising effects. For example, from Table 2, it can be seen that incremental AUC accounted for only 14 to $38 \%$ of total AUC.

For methods 2, 4 and 5 there are insufficient data to make any recommendation.

Method 3, incremental AUC, is the method recommended by the Food and Agriculture Organization (1998), and the method used for most calculations of GI up to the present time. Since use of different methods of calculating AUC results in different GI values (Tables 2 and 3), one argument for retaining this method is that adoption of a new method might render all previous GI values inaccurate. However, this is not a satisfactory argument if the method is wrong. This raises the question as to whether there is any objective advantage of method 3 (incremental AUC) over methods 2 (incremental $\mathrm{AUC}_{\text {cut }}$ ), 4 (incremental $\mathrm{AUC}_{\min }$ ) and 5 (net incremental AUC). Recently the performance of some of these and other methods of calculating incremental AUC was compared using a data-set of five foods tested in forty-seven normal subjects (Wolever, 2004b) (Table 2).

GI values based on the use of incremental $\mathrm{AUC}_{\min }$ (method 4) and net incremental AUC (method 5) did not agree well with those derived from the recommended method, and GI values based on incremental $\mathrm{AUC}_{\text {min }}$ were significantly less than those from the recommended method (Table 2). This in itself does not mean that these methods should not be used. However, GI values based on incremental $\mathrm{AUC}_{\min }$ were significantly correlated with the subjects' glycaemic response to the reference food (oral glucose), suggesting that this is not a good method of determining GI, since the GI values obtained depend on the glucose tolerance status of the subject. In addition, the use of incremental $\mathrm{AUC}_{\max }$ is not recommended because the SD of the GI values, 24.0, is $18 \%$ greater than that for the recommended method. Incremental $\mathrm{AUC}_{\text {cut }}$ produced GI values which agreed well with the recommended method, but the SD of the GI values tended to be greater than for the recommended method, and although the difference was small, it was present for each of the five foods, and the difference was statistically significant by paired $t$ test.

The length of the time period during which post-ingestion testing is done, as well as subject characteristics, may play a significant role. In certain subjects, foods with readily available $\mathrm{CHO}$, such as white bread, may induce a sharp and rapid decline in blood glucose within the $120 \mathrm{~min}$ period, and a hypoglycaemia in the late postprandial phase. Thus, the GI of pasta products as calculated from the $2 \mathrm{~h}$ AUC in healthy elderly men were not significantly different from the white reference bread despite prominent differences in course of glycaemia, with a low but sustained net increment in blood glucose following the pasta. The small glucose

Table 3. Areas under the curve (AUC) calculated in different ways $(\mathrm{mmol} \times \mathrm{min} / \mathrm{l})$

\begin{tabular}{|c|c|c|c|c|c|c|c|}
\hline Method & & Food & Gluc 1 & Gluc 2 & Gluc 3 & Mean glucose & GI \\
\hline 1 & Total AUC & $654 \cdot 2$ & $819 \cdot 4$ & $758 \cdot 8$ & $785 \cdot 1$ & $787 \cdot 8$ & 83 \\
\hline 2 & $\mathrm{AUC}_{\text {cut }}$ & $92 \cdot 2$ & $309 \cdot 4$ & 91.0 & $264 \cdot 3$ & $221 \cdot 6$ & 42 \\
\hline $3^{*}$ & Incremental AUC & $92 \cdot 2$ & $309 \cdot 4$ & $147 \cdot 0$ & $264 \cdot 3$ & $240 \cdot 2$ & 38 \\
\hline 4 & $A \cup C_{\min }$ & $173 \cdot 0$ & $309 \cdot 4$ & $187 \cdot 6$ & $264 \cdot 3$ & $253 \cdot 8$ & 68 \\
\hline 5 & Net AUC & $72 \cdot 2$ & $309 \cdot 4$ & $145 \cdot 6$ & $264 \cdot 3$ & $239 \cdot 8$ & 30 \\
\hline
\end{tabular}

Gluc, glucose measurement; Gl, glycaemic index.

${ }^{*}$ Method shown on Fig. 12. 
AUC following white bread was related to a substantially higher insulin response. More studies are needed to evaluate if the $2 \mathrm{~h}$ time period commonly used needs to be modified in certain subjects (Granfeldt et al. 1991).

\section{Calculation of glycaemic index}

How should the ratio be calculated?

Scientific background. At present, a ratio we shall call f:r is calculated for each subject where $\mathrm{f}$ is an individual subject's incremental AUC after consuming the test food and $\mathrm{r}$ is the incremental AUC for the same subject after consuming the reference food. The individual values of $\mathrm{f}: \mathrm{r}$ are then averaged over all subjects to give the GI for the test food. This method will be referred to as the mean of the ratios.

Another method would be to calculate F:R where $\mathrm{F}$ is the mean incremental AUC for a group of subjects after consuming the test food and $\mathrm{R}$ is the mean incremental AUC for the same group of subjects after consuming the reference food. This method is called the ratio of the means. Using the same set of data, these methods do not yield exactly the same result (Wolever et al. 2003). The advantage of the mean of the ratios method is that one can derive an error term more easily, which allows the GI of different foods to be compared statistically. The disadvantage is that this may require more tests (to repeat the reference food testing in each subject).

Recommendation. Whatever the remaining points still to be elucidated, we recommend to calculate AUC using the incremental AUC (method 3), ignoring area under the baseline. We recommend calculating GI as the mean of the individual ratios. These calculations are explained in detail below (please refer to Fig. 12 and Table 3).

Illustration and formulas. The general formula for calculating AUC is as follows:

Assuming that at times $\mathrm{t}_{0}, \mathrm{t}_{1}, \ldots \mathrm{t}_{\mathrm{n}}$ (here equalling $0,15 \ldots$ $120 \mathrm{~min}$, respectively), the blood glucose concentrations are $\mathrm{G}_{0}, \mathrm{G}_{1}, \ldots \mathrm{G}_{\mathrm{n}}$, respectively:

$\mathrm{AUC}=\sum_{\mathrm{n}}^{\mathrm{x}=1} \mathrm{Ax}$,

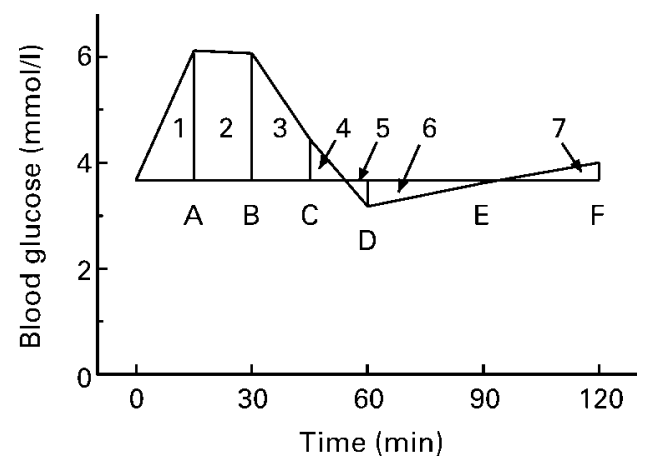

Fig. 12. Calculation of incremental area under the curve. where Ax is the AUC for the xth time interval, and the xth time interval is the interval between times $t_{x-1}$ and $t_{x}$.

For the first time interval (i.e. $\mathrm{x}=1$ ):

if $\mathrm{G}_{1}>\mathrm{G}_{0}, \mathrm{~A}_{1}=\left(\mathrm{G}_{1}-\mathrm{G}_{0}\right) \times\left(\mathrm{t}_{1}-\mathrm{t}_{0}\right) / 2$;

otherwise, $\mathrm{A}_{1}=0$.

For other time intervals (i.e. $\mathrm{x}>1$ ):

if $\mathrm{G}_{\mathrm{x}} \geq \mathrm{G}_{0}$ and $\mathrm{G}_{\mathrm{x}-1} \geq \mathrm{G}_{0}, \quad \mathrm{Ax}=\left(\left(\left(\mathrm{G}_{\mathrm{x}}-\mathrm{G}_{0}\right) / 2\right)\right.$

$\left.+\left(\mathrm{G}_{\mathrm{x}-1}-\mathrm{G}_{0}\right) / 2\right) \times\left(\mathrm{t}_{\mathrm{x}}-\mathrm{t}_{\mathrm{x}-1}\right) / 2$;

if $\mathrm{G}_{\mathrm{x}} \geq \mathrm{G}_{0}$ and $\mathrm{G}_{\mathrm{x}-1}<\mathrm{G}_{0}, \quad \mathrm{Ax}=\left(\left(\mathrm{G}_{\mathrm{x}}-\mathrm{G}_{0}\right)^{2} /\right.$

$\left.\left(\mathrm{G}_{\mathrm{x}}-\mathrm{G}_{\mathrm{x}-1}\right)\right) \times\left(\mathrm{t}_{\mathrm{x}}-\mathrm{t}_{\mathrm{x}-1}\right) / 2$;

if $\mathrm{G}_{\mathrm{x}}<\mathrm{G}_{0}$ and $\mathrm{G}_{\mathrm{x}-1} \geq \mathrm{G}_{0}, \quad A x=\left(\left(\mathrm{G}_{\mathrm{x}-1}-\mathrm{G}_{0}\right)^{2} /\right.$

$\left.\left.\mathrm{G}_{\mathrm{x}-1}-\mathrm{G}_{\mathrm{x}}\right)\right) \times\left(\mathrm{t}_{\mathrm{x}}-\mathrm{t}_{\mathrm{x}-1}\right) / 2$;

if $\mathrm{G}_{\mathrm{x}}<\mathrm{G}_{0}$ and $\mathrm{G}_{\mathrm{x}-1}<\mathrm{G}_{0}, A \mathrm{x}=0$.

Application of the formula to the above-cited example (incremental areas for segments 1-7):

1: $\mathrm{A} / 2 \times 15=1.22 \times 15=18.30 \mathrm{mmol} \times \mathrm{min} / \mathrm{l}$

2: $(\mathrm{A} / 2+\mathrm{B} / 2) \times 15=(1 \cdot 22+1 \cdot 195) \times 15=36 \cdot 23$

$\mathrm{mmol} \times \mathrm{min} / \mathrm{l}$

3: $(\mathrm{B} / 2+\mathrm{C} / 2) \times 15=(1 \cdot 195+0 \cdot 385) \times 15=23 \cdot 70$

$\mathrm{mmol} \times \mathrm{min} / \mathrm{l}$;

4: $\left(\mathrm{C}^{2} /(\mathrm{C}-\mathrm{D})\right) \times 15 / 2=(0.593 /(0 \cdot 77+0.50)) \times 7 \cdot 5=$ $3.50 \mathrm{mmol} \times \mathrm{min} / \mathrm{l}$;

5 and 6: area below baseline not included, $=0$;

7: $\left(\mathrm{F}^{2} /(\mathrm{F}-\mathrm{E})\right) \times 30 / 2=(0 \cdot 109 /(0 \cdot 33+0 \cdot 06)) \times 15=$ $4.19 \mathrm{mmol} \times \mathrm{min} / \mathrm{l}$;

Incremental $\mathrm{AUC}=18 \cdot 30+36 \cdot 23+23 \cdot 70+3 \cdot 59+$ $4 \cdot 19=86 \cdot 0$.

Tables 4 and 5 show blood glucose concentrations and illustrate the calculation of incremental AUC.

\section{Interlaboratory values and variation}

How comparable are GI values measured by different laboratories?

Scientific background. Mean GI values measured in different laboratories vary. Fig. 13 shows the distribution of mean GI values reported for several foods (Foster-Powell et al. 2002). By just looking at these data, it is difficult to draw conclusions about whether the variation represents methodological differences, true differences between foods of similar description, or random variation. It is also difficult to determine the magnitude of true random variation of mean GI values between different laboratories. For some foods, such as apple, lentils and brown bread, the interlaboratory SD (the SD of the mean GI calculated within each laboratory) of the GI values is $<10$, whereas for others, such as potato, the interlaboratory SD of the mean values is $>20$. An interlaboratory SD of $<10$ would likely be acceptable because this would mean that the $95 \%$ CI for any GI value would be $< \pm 20$. Such a value is larger than ideal, but does allow one to know with confidence that the GI values of many low-GI foods (for example, GI of lentils $=28$ ) will almost always have a lower GI than many high-GI foods (for example, GI of bread = 71) when determined by different laboratories using standardised and correct methods. However, if the interlaboratory SD was much over 10 , then the $\mathrm{CI}$ formed by combining the mean 
Table 4. Blood glucose concentrations (mmol/l)

\begin{tabular}{lccccccr}
\hline & \multicolumn{7}{c}{ Time (min) } \\
\cline { 2 - 7 } & 0 & 15 & 30 & 45 & 60 & 90 & 120 \\
\hline Food & 4.85 & 6.78 & 6.84 & $6 \cdot 15$ & 5.76 & 4.01 & 4.76 \\
Gluc 1 & 4.25 & 5.21 & 7.84 & 7.68 & 7.32 & 6.91 & 6.97 \\
Gluc 2 & 5.11 & 6.91 & 7.74 & 6.89 & 4.76 & 6.62 & 6.11 \\
Gluc 3 & 4.34 & 5.45 & 8.08 & 7.49 & 7.56 & 6.25 & 5.31 \\
\hline
\end{tabular}

Gluc, glucose measurement.

Table 5. Illustration of calculation of incremental area under the curve with one set of blood glucose concentrations values

\begin{tabular}{llllllll}
\hline & \multicolumn{7}{c}{ Time (min) } \\
\cline { 2 - 7 } & 0 & 15 & 30 & 45 & 60 & 90 & 120 \\
\hline Concentrations & 3.67 & 6.11 & 6.06 & 4.44 & 3.17 & 3.61 & 4.00 \\
Increment $_{\text {Increment label* }}$ & - & 2.44 & 2.39 & 0.77 & -0.50 & -0.06 & 0.33 \\
\hline
\end{tabular}

* See Fig. 12

GI from each laboratory into an overall mean would become so large that it would be difficult to distinguish between foods, and the GI would lose practical utility.

Recently an interlaboratory study was performed to estimate the between-laboratory variation of mean GI values (Wolever et al. 2003). It included five laboratories, which used capillary blood sampling to determine the GI values (glucose $=100$ ) of four centrally provided foods and locally obtained white bread (Fig. 14). The pooled interlaboratory SD of the GI values for the five foods was approximately 9.

From this the probability of two laboratories obtaining GI values for the same food within limits from 0 to 20 have been calculated as $1-2 \mathrm{~N}$, where $\mathrm{N}$ equals the area under the normal distribution curve between $-\mathrm{C}$ and minus infinity, where $\mathrm{C}=\mathrm{D} /(\mathrm{SD} \times \sqrt{ } 2)$, where $\mathrm{D}$ is the GI difference and $\mathrm{SD}$ is the interlaboratory SD (Fig. 15). With an interlaboratory SD of 9, the chance of two laboratories obtaining a GI value for the same food which differs by less than 15 is about $76 \%$ (i.e. a $24 \%$ chance that the difference is greater than 15$)$. If the interlaboratory SD could be decreased to 8,7 , 6 or 5 , the chance of obtaining a GI difference of $<15$ increases to $82,87,92$ and $97 \%$, respectively. With an interlaboratory SD of 9 , there is a $95 \%$ chance that the difference in GI value obtained for the same food in two different laboratories is $<25$. If the interlaboratory SD were decreased to $8,7,6$, or 5 , the respective difference would fall to $23,20,17$ and 14 . It should be noted that these calculations are based on exactly two laboratories. The probability of such differences between any two of a group of laboratories will be higher.

Conclusion. When standardised methods are applied to determining the GI (glucose = 100) of identical high-CHO foods, the interlaboratory SD of GI values is approximately 9 .

\section{How to handle outlier values?}

The advantage in dealing with GI values is that by indexing the individual glycaemic response to a standard, the variation that occurs due to several factors, for example, subject and food-related ones, the between-individual variation is minimised (Wolever, 1990a). Checking the data obtained for the individual subjects may sometimes reveal values that are implausible by comparison with the rest of the data from other subjects. Outliers are particularly important because they can have considerable influence on the results of a statistical analysis (Altman, 1991). Outliers could be due to incorrect subject preparation (for example, non-fasting), analytical error, or errors in data calculation. In the absence of errors, an outlier could be due to an unrepresentative response to the standard or test food or to the subject having a true idiosyncratic response. An unrepresentative response to the standard food is suspected if the subject's GI values for other test foods are also outliers in the same direction, or if there is large variability for the repeated standard tests (Wolever et al. 1991). If outliers are excluded, this fact should be stated, and the results including the outlying point(s) should be given along with the position of the outlying point(s) in relation to the rest of the data, i.e. number of SD from the mean (including the outlier(s)). This will allow others to assess the impact of removing the outlier(s) on the results and conclusions and to form an opinion of the reasonableness of excluding the outlier(s).

Recommendation. There is no general advice or rule in statistical analysis to exclude outlying data from the complete data-set. Nevertheless, if an outlying value does not seem to be plausible or if any mistake in determining this data point is evident, this value could be regarded as suspicious and removed from the data-set (Altman, 1991). Therefore, under certain circumstances and for reasons of practicability an outlier could be removed from the data-set without reassessment of that particular GI value.

\section{Glycaemic index of mixed meals}

What is the impact of measurement in the context of mixed meals? Can we measure the GI of a meal (composed of different foods)? 


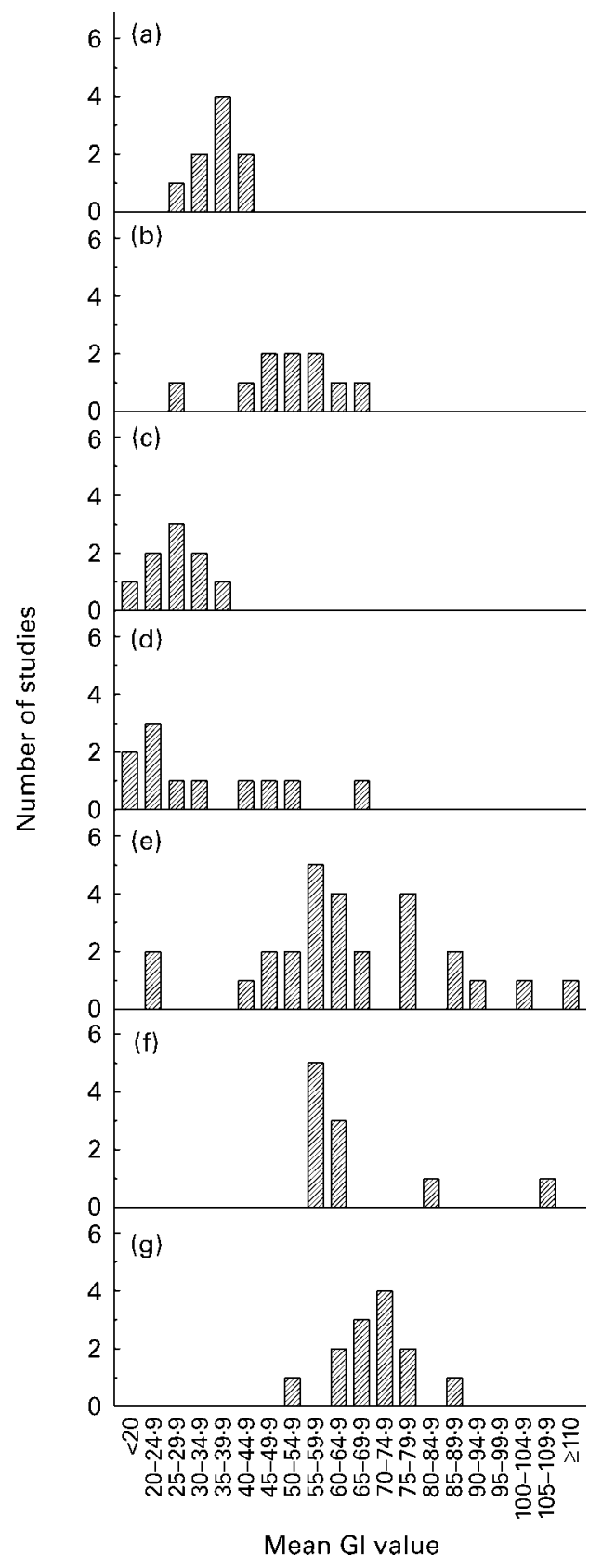

Fig. 13. Distribution of mean glycaemic index values (glucose $=100$ ) of seven foods reported in the literature. (a), Apple, $n$ 9, mean 37.4 (SD 5.1); (b), banana, $n$ 10, mean 51.7 (SD 11.2); (c), lentils, $n 9$, mean 27.6 (SD 6.1); (d), kidney beans, $n 11$, mean 34.2 (SD 16.9); (e), potato, $n 27$, mean 65.2 (SD 20.8); (f), sucrose, $n 10$, mean 68.1 (SD 16.3); (g), brown bread, $n 13$, mean 70.5 (SD 8.4).

Scientific background. In general, foods are not eaten alone but in the context of a meal. This leads to two questions:

(1) Does a food have the same GI when eaten alone or during a meal?

(2) Can we predict the GI of a meal by the GI of the different foods consumed within the meal, or, in another way, can we predict the glucose response to a meal by the glucose responses to the different components within this meal?

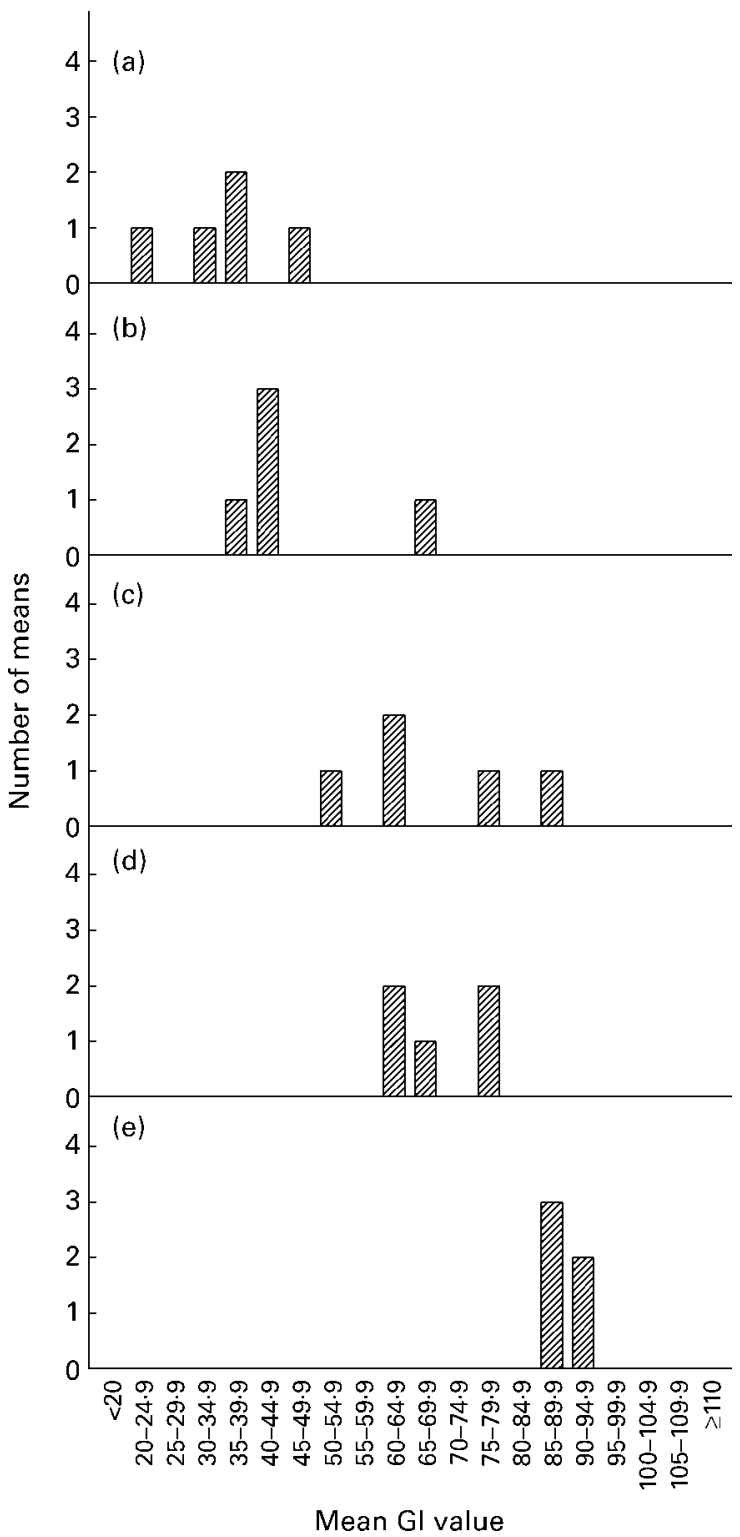

Fig. 14. Distribution of glycaemic index (Gl) values (glucose $=100$ ) of four centrally provided foods and white bread determined by five experienced laboratories using standardised methodology. (a), Pearled barley, mean 35.5 (SD 8.2); (b), spaghetti, mean 47.7 (SD 12.6); (c), rice, mean 68.5 (SD 12.2); (d), white bread, mean 71.2 (SD 7.3); (e), instant potato, mean 91.2 (SD 4.8).

First of all, the GI of a single food is dependent on the composition of this food. Actually, different elements can affect the GI of a food, such as the presence of fat (Collier \& O'Dea, 1983), the presence of protein (Granfeldt et al. 1991), the presence of some anti-nutrients (Thorne et al. 1983), and acidity or the presence of acidic compounds (Liljeberg et al. 1995; Liljeberg \& Bjorck, 1996, 1998). Moreover, other factors linked to the quality and the quantity of $\mathrm{CHO}$ present in the food can also affect its GI (see also Table 1). When a food is included into a meal, the glucose response per se to this meal will not be the same as the glucose response to the single food. Indeed, the other macronutrients (fat, protein, $\mathrm{CHO}$ and other nutrients) 


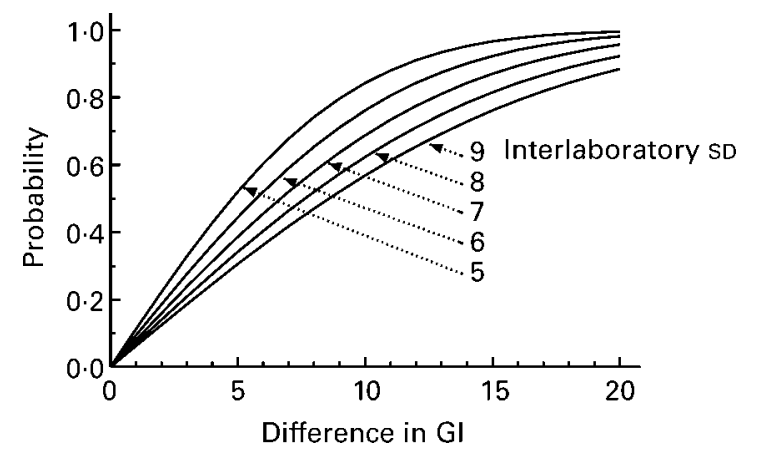

Fig. 15. Effect of changes in interlaboratory SD on the probability that the difference in glycaemic index $(\mathrm{Gl})$ (glucose $=100$ ) for the same food tested in two different laboratories on one occasion (with $n 8-10$ subjects) is less than or equal to 0 to 20 .

provided by the co-ingested foods have an influence on both glucose and insulin responses.

However, it remains the quality and the quantity of $\mathrm{CHO}$ that determine the glucose response to the meal (Wolever \& Bolognesi, 1996b). A study evaluated the glucose response to six starch-rich foods with varying GI (beans, lentils, rice, spaghetti, potato and bread) either tested alone or in mixed meals (Bornet et al. 1987). All tests contained $50 \mathrm{~g} \mathrm{CHO,}$ and meals were adjusted to bring the same amount of fat, protein, water and energy, but not the same amount of fibres. The study demonstrated that, in respect to glucose-raising potential, the hierarchy between foods tested alone (GI testing) was respected once the same foods were tested in these meals. This means that the GI concept remains discriminating in the context of a meal (Bornet et al. 1987).

Concerning the glycaemic response to a meal, several authors agree that this can be predicted by the GI of each food composing this meal (Collier et al. 1986; Wolever \& Jenkins, 1986; Chew et al. 1988), whereas others think such a prediction is not justified (Coulston et al. 1987), this even though some of their results seem to differ from their conclusions, as commented in Augustin et al. (2002).

Very recently Flint et al. (2004) published data on thirteen breakfast meals and a control meal of differing composition. In their study they could not show that the GI of mixed breakfast meals, as calculated by using GI table values, correlated with the GI as measured in vivo. A stronger relationship was observed for either fat or protein or energy content than for $\mathrm{CHO}$ alone. These results are not unexpected because, although the test meals contained $50 \mathrm{~g}$ available $\mathrm{CHO}$, there was a large range of fat (3-42 $\mathrm{g}$ ), protein $(5-28 \mathrm{~g})$ and energy $(1130-2990 \mathrm{~kJ})$. In the face of such large differences in fat and protein, nutrients, which are known to influence glucose and insulin responses
(Nuttall et al. 1985; Ercan et al. 1994), it is expected that GI of the meal components alone would not predict glycaemic responses. Another problem is that Flint et al. (2004) determined meal GI based on food GI values obtained from the international table of GI (Foster-Powell \& Brand-Miller, 1995 ) and it is not clear whether the correct GI values were ascribed to the foods used. For example, Finnish and German breads are ascribed a GI value of 92 (white bread $=100$ ) based on entries 45 to 54 in the table, which are for rye breads with a range of GI values from 58 to 123 ; of these ten different breads, only one actually was a German bread and it had a GI value of 58 (Schauberger $e t$ al. 1978). The value used for oatmeal, entries 116 and 117 , are not for oat meal but for raw oat bran (high-fibre extract of oats), etc. Accordingly, the data presented in the paper by Flint et al. (2004) are difficult to interpret and render the conclusions of these authors that in general the GI of mixed meals can not be predicted invalid. Instead, available evidence indicates that GI values of composite high-CHO meals can be predicted well based on the meal components.

Recommendations. We recommend calculating the GI of a meal from the separately measured GI of the individual foods. For most accurate prediction, and particularly in studies testing the utility of the GI in mixed meals, the GI values of the individual foods should be measured rather than estimated from GI tables.

Examples for the calculation of the glycaemic index of mixed meals. Tables 6 and 7 show the contribution to meal GI of breakfast and lunch foods.

\section{Glucose analysis}

What is the standard method of measurement of glucose concentration in body fluids used in GI determinations?

Glucose concentration can be determined by enzymic methods such as used normally in blood gluco-meters (used for diabetics) or enzymic determination in plasma samples. However, different methods for the measurement of glucose may differ in their precision.

Recommendation. The precision of the method chosen should be evaluated. Ideally, methods with a $\mathrm{CV}>3 \%$ should not be used for scientific purpose. Glucose methods should return $98 \%$ of a glucose spike to be acceptable.

The precision and accuracy of the method chosen should be evaluated. Methods for glucose estimation with a $\mathrm{CV}>3 \%$ will introduce significant analytical variation into the measurement of GI. Accuracy may be estimated from the recovery of added glucose (a 'glucose spike') and

Table 6. Breakfast

\begin{tabular}{lcccc}
\hline Mixed meal & CHO $(\mathrm{g})$ & Total CHO $(\%)$ & Gl & $\begin{array}{l}\text { Contribution } \\
\text { to meal Gl }\end{array}$ \\
\hline Breakfast biscuits $(50 \mathrm{~g})$ & 36 & 40 & 52 & $40 \% \times 52=21$ \\
Milk + chocolate powder $(250 \mathrm{ml})$ & 30 & 33 & 38 & $33 \% \times 38=13$ \\
One banana & 25 & 27 & 58 & $27 \% \times 58=16$ \\
Totals & 91 & 100 & & Meal Gl $=50$ \\
\hline
\end{tabular}

$\mathrm{CHO}$, carbohydrate; GI, glycaemic index. 
Table 7. Lunch

\begin{tabular}{|c|c|c|c|c|}
\hline Mixed meal & $\mathrm{CHO}(\mathrm{g})$ & Total $\mathrm{CHO}(\%)$ & GI & $\begin{array}{l}\text { Contribution } \\
\text { to meal Gl }\end{array}$ \\
\hline Beetroots $(100 \mathrm{~g})$ & 9 & 18 & 64 & $18 \% \times 64=12$ \\
\hline Mashed potatoes $(150 \mathrm{~g})$ & 20 & 39 & 85 & $39 \% \times 85=33$ \\
\hline Beefsteak $(125 \mathrm{~g})$ & 0 & 0 & 0 & 0 \\
\hline Yoghurt (125g) & 6 & 12 & 36 & $12 \% \times 36=4$ \\
\hline One apple & 16 & 31 & 32 & $31 \% \times 32=10$ \\
\hline Totals & 51 & 100 & & Meal GI = 59 \\
\hline
\end{tabular}

$\mathrm{CHO}$, carbohydrate; GI, glycaemic index.

this should be $100 \pm 2 \%$ in order not to render the GI measurement potentially inaccurate.

\section{Conclusions}

Based on the currently available science described in the present review, the following conclusions and recommendations are made:

(1) At least ten test subjects should be tested to obtain a sufficient statistical power;

(2) Inclusion of both sexes in a study is acceptable;

(3) For GI measurement the $\mathrm{CHO}$ portion should be based on available $\mathrm{CHO}$

(4) A test dose of $50 \mathrm{~g}$ available $\mathrm{CHO}$ is recommended;

(5) For foods with a low $\mathrm{CHO}$ content it is justified to lower the test dose to $25 \mathrm{~g}$;

(6) The reference food should be measured at least twice.

(7) The use of healthy human volunteers is recommended;

(8) Fluid ingestion, $250 \mathrm{ml}$, should take place within 5-10 min;

(9) Solids and semi-solids ingestion within 10-15 min;

(10) Glucose or white bread are recommended as reference foods;

(11) The evening before a test each subject should consume a meal of choice and repeat that meal before each subsequent test. Unusual vigorous physical activity should be avoided;

(12) Test foods should be randomised in blocks of maximal 6;

(13) The total duration of the tests should not exceed 4 months;

(14) In the case of testing multiple foods, a reference test should be done at the beginning and a repetition should take place after every 6-8 weeks;

(15) Glucose measurement alone is appropriate;

(16) For more mechanistic and/or metabolic studies, measurement of both glucose and insulin is recommended;

(17) Blood sampling times should be at 0 min (baseline sample), followed by $15,30,45,60,90$ and 120 min after starting to eat the test meal;

(18) AUC calculation should be based on incremental AUC, ignoring area under the baseline;

(19) It is recommended to calculate GI as the mean of the individual ratios.

\section{Future research and development directions}

Some important directions for future research concerning the measurement of GI can be given.

Not enough data exist to determine exactly how many repeats of a reference food test should be done.
Are mean and variation of GI data comparable in:

(a) Insulin sensitive $v$. insulin resistant non-diabetic subjects?

(b) Obese, overweight and lean subjects?

(c) Normal children $v$. normal adults?

(d) Various ethnic groups?

(e) Different age states - children, middle-aged, elderly?

(f) Type 1 or 2 diabetes?

A recommendation was given to use a test dose not smaller than $25 \mathrm{~g}$. What is the effect of doses of less than $25 \mathrm{~g}$, what is the lowest possible dose to still get reliable data?

A recommendation was given to test in the morning after an overnight fast. Do other test times of the day lead to different results, and which is most representative of a longterm health impact?

Does the addition of significant amounts of RS to foods have an impact on GI?

Does a reduction of glycaemic response through a reduction of available $\mathrm{CHO}$, while maintaining total $\mathrm{CHO}$ (available + all non-available $\mathrm{CHO}$ ) lead to metabolic and health effects that are similar or different to those observed after intake of equal amounts of available $\mathrm{CHO}$ that differ in GI? (This question is currently being addressed in another 'ILSI Europe, Carbohydrates Task Force' initiative.)

Studies that address the long-term health impact of GI and other measures of reducing the glycaemia of foods should be evaluated in order to define which mode of expression of the glycaemic concept is capable of meeting regulatory needs in regard of labelling enforcement, if any.

Basically there are not a large number of high-CHO foods and drinks on the current market that result in a low glycaemic response after consumption. When considering the narrow and high range of glycaemic response that is characteristic of the current Western diet, the potential benefits observed with a 'low-GI diet' may imply that, provided consumers could have access to an extended list of low-GI foods, the benefits could be magnified. Accordingly, the development and manufacturing of 'high-CHO but lowGI' foods may be desired for health purposes.

\section{Acknowledgements}

This work was performed by an ILSI Europe invited working group, who had multiple meetings in the period 2002-2004. The work was supported by an unconditional grant from the 'Dietary Carbohydrates Task Force' of the European Branch of the 'International Life Sciences Institute' (ILSI Europe). Industry members of this task 
force are CocaCola, Cerestar-Cargill, Danisco, Danone, Kellogg, Masterfoods, Südzucker, Unilever, Royal Cosun. For further information about ILSI Europe, call +32 2 771.00 .14 or email info@ilsieurope.be. The opinions expressed herein are those of the authors and do not necessarily represent the views of ILSI or ILSI Europe.

\section{References}

Altman DG (1991) Practical Statistics for Medical Research. London: Chapman \& Hall.

Arvidsson-Lenner R, Asp NG, Axelsen M, Bryngelsson S, Haapa E, Jarvi A, Karlstrom B, Raben A, Sohlstrom A, Thorsdottir I \& Vessby B (2004) Glycemic index. Scandinavian Journal of Nutrition 48, 84-89.

Asp NG (1995) Classification and methodology of food carbohydrates as related to nutritional effects. American Journal of Clinical Nutrition 61, Suppl., 930S-937S.

Attvall S, Fowelin J, Lager I, Von Schenck H \& Smith U (1993) Smoking induces insulin resistance - a potential link with the insulin resistance syndrome. Journal of Internal Medicine 233, $327-332$

Augustin LS, Dal Maso L, La Vecchia C, Parpinel M, Negri E, Vaccarella S, Kendall CW, Jenkins DJ \& Francesch S (2001) Dietary glycemic index and glycemic load, and breast cancer risk: a case-control study. Annals of Oncology 12, 1533-1538.

Augustin LS, Franceschi S, Jenkins DJA, Kendall CWC \& La Vecchia C (2002) Glycaemic index in chronic disease: a review. European Journal of Clinical Nutrition 56, 1049-1071.

Augustin LS, Gallus S, Bosetti C, Levi F, Negri E, Franceschi S, Dal Maso L, Jenkins DJA, Kendall CKW \& La Vecchia C (2003) Glycaemic index and glycaemic load in endometrial cancer. International Journal of Cancer 105, 404-407.

Benton D, Ruffin MP, Lassel T, Nabb S, Messaoudi M, Vinoy S, Desor D \& Lang V (2003) The delivery rate of dietary carbohydrates affects cognitive performance in both rats and humans. Psychopharmacology (Berlin) 166, 86-90.

Bjorck I \& Elmstahl HL (2003) The glycaemic index: importance of dietary fibre and other food properties. Proceedings of the Nutrition Society 62, 201-206.

Björck I, Liljeberg H \& Östmann E (2000) Low glycaemic index foods. British Journal of Nutrition 83, Suppl. 1, S149-S155.

Bland M \& Altman D (1986) Statistical methods for assessing agreement between two methods of clinical measurements. Lancet i, 307-310.

Bornet FR, Costagliola D, Rizkalla SW, Blayo A, Fontvieille AM, Haardt MJ, Letanoux M, Tchobroutsky G \& Slama G (1987) Insulinaemic and glycaemic indexes of six starch-rich foods taken alone and in a mixed meal by type 2 diabetics. American Journal of Clinical Nutrition 45, 588-595.

Bouché C, Rizkalla SW, Luo J, Vidal H, Veronese A, Pacher N, Fouquet C, Lang V \& Slama G (2002) Five-week, low-glycemic index diet decreases total fat mass and improves plasma lipid profile in moderately overweight nondiabetic men. Diabetes Care 25, 822-888.

Brand JC, Colagiuri S, Crossman S, Allen A, Roberts DCK \& Truswell AS (1991) Low-glycaemic index foods improve longterm glycaemic control in NIDDM. Diabetes Care 14, 95-101.

Brand-Miller J, Hayne S, Petocz P \& Colagiuri S (2003a) Low glycaemic index diets in the management of diabetes. A metaanalysis of randomized controlled trials. Diabetes Care 26, 2261-2267.

Brand-Miller JC (1994) The importance of glycaemic index in diabetes. American Journal of Clinical Nutrition 59, Suppl., $747 \mathrm{~S}-752 \mathrm{~S}$.
Brand-Miller JC (2004) Postprandial glycemia, glycemic index, and the prevention of type 2 diabetes. American Journal of Clinical Nutrition 80, 243-244.

Brand-Miller JC, Thomas M, Swan V, Ahmad ZI, Petocz P \& Colagari S (2003b) Physiological validation of the concept of glycemic load in lean young adults. Journal of Nutrition 133, $2732-2788$

Brighenti F, Casiraghi MC, Canzi E \& Ferrari A (1999) Effect of consumption of a ready-to-eat breakfast cereal containing inulin on the intestinal milieu and blood lipids in healthy male volunteers. European Journal of Clinical Nutrition 53, 726-733.

Brouns F (1998) Gastric emptying as a regulatory factor in fluid uptake. International Journal of Sports Medicine 19, S125-S128.

Brouns F, Senden J, Beckers EJ \& Saris WHM (1995) Osmolarity does not affect the gastric emptying rate of oral rehydration solutions. Journal of Parenteral and Enteral Nutrition 19, 387-391.

Campbell JE, Glowczewski T \& Wolever TMS (2003) Controlling subjects prior diet and activities does not reduce within-subject variation of post-prandial glycaemic responses to foods. Nutrition Research 23, 621-629.

Champ M, Langkilde AM, Brouns F, Kettlitz B \& Le Bail-Collet Y (2003) Advances in dietary fibre characterisation II. Consumption, chemistry, physiology and measurement of resistant starch: implications for health and food labelling. Nutrition Research Reviews 16, 143-161.

Chew I, Brand JC, Thorburn AW \& Truswell AS (1988) Application of glycaemic index to mixed meals. American Journal of Clinical Nutrition 47, 53-56.

Collier G \& O'Dea K (1983) The effect of coingestion of fat on the glucose, insulin, and gastric inhibitory polypeptide responses to carbohydrate and protein. American Journal of Clinical Nutrition 37, 941-944.

Collier GR, Wolever TM, Wong GS \& Josse RG (1986) Prediction of glycaemic response to mixed meals in noninsulin dependent diabetic subjects. American Journal of Clinical Nutrition 44, 349-352.

Cordain L, Eaton SB, Brand-Miller J, Lindeberg S \& Jensen C (2002) An evolutionary analysis of the aetiology and pathogenesis of juvenile-onset myopia. Acta Ophthalmologica Scandinavica 80, 125-135.

Coulston AM, Hollenbeck CB, Swislocki AL \& Reaven GM (1987) Effect of source of dietary carbohydrate on plasma glucose and insulin responses to mixed meals in subjects with NIDDM. Diabetes Care 10, 395-400.

Dillon R (1965) Importance of hematocrit in interpretation of blood sugar. Diabetes 14, 672-678.

Ellison JM, Stegmann JM, Colner SL, Michael RH, Sharma MK, Ervin KR \& Horwitz DL (2002) Rapid changes in postprandial blood glucose produce concentration differences at finger, forearm, and thigh sampling sites. Diabetes Care 25, 961-964.

Englyst H, Åkerberg A, Liljeberg H, Granfeldt Y, Drews A \& Björck I (1998) An in vitro method based on chewing, to predict resistant starch content in foods allows parallel determination of potentially available starch and dietary fibre. Journal of Nutrition 128, 651-660.

Englyst HN, Kingman SM, Hudson GJ \& Cummings JH (1996) Measurement of resistant starch in vitro and in vivo. British Journal of Nutrition 75, 749-755.

Englyst KN, Vinoy S, Englyst HN \& Lang V (2003) Glycaemic index of cereal products explained by their content of rapidly and slowly available glucose. British Journal of Nutrition 89, $329-340$ 
Ercan N, Nuttall FQ \& Gannon M (1994) Effect of added fat on the plasma glucose and insulin response to ingested potato given in various combinations as two meals in normal individuals. Diabetes Care 17, 1453-1459.

Flint A, Møller BK, Raben A, Pedersen D, Tetens I, Holst JJ \& Astrup A (2004) The use of glycaemic index tables to predict glycaemic index of composite breakfast meals. British Journal of Nutrition 91, 979-989.

Folch N, Peronnet F, Massicotte D, Charpentier S \& Lavoie C (2003) Metabolic response to a large starch meal after rest and exercise; comparison between men and women. European Journal of Clinical Nutrition 57, 1107-1115.

Food and Agriculture Organization (1998) Carbohydrates in Human Nutrition: Report of a Joint FAO/WHO Expert Consultation, Rome, 14-18 April 1997. FAO Food and Nutrition Paper no. 66. Rome: FAO.

Foster-Powell K \& Brand-Miller JC (1995) International table of glycaemic index. American Journal of Clinical Nutrition 62 , 871S-893S

Foster-Powell K, Holt SHA \& Brand-Miller JC (2002) International table of glycaemic index and glycaemic load values. American Journal of Clinical Nutrition 76, 5-56.

Franceschi S, Dal Maso L, Augustin L, Negri E, Parpinel M, Boyle P, Jenkins DJA \& La Vecchia C (2001) Dietary glycaemic load and colorectal cancer risk. Annals of Oncology 12, $173-178$.

Frati AC, Iniestra F \& Ariza CR (1996) Acute effect of cigarette smoking on glucose tolerance and other cardiovascular risk factors. Diabetes Care 19, 112-118.

Frayn KN \& Macdonald IA (1992) Methodological considerations in arterialization of venous blood. Clinical Chemistry 38, $316-317$.

Frayn KN, Whyte PL, Benson HA, Earl DJ \& Smith HA (1989) Changes in forearm blood flow at elevated ambient temperature and their role in the apparent impairment of glucose tolerance. Clinical Science 76, 323-328.

Frost G, Leeds A, Dore D, Madeiros S, Brading S \& Dornhorst A (1999) Glycaemic index as a determinant of serum HDLcholesterol concentration. Lancet 353, 1045-1048.

Frost G, Leeds A, Trew G, Margara R \& Dornhorst A (1998) Insulin sensitivity in women at risk of coronary heart disease and the effect of a low glycaemic index diet. Metabolism 47, $1245-1251$

Frost G, Wilding J \& Beecham J (1994) Dietary advice based on the glycaemic index improves dietary profile and metabolic control in type 2 diabetic patients. Diabetic Medicine 11, 397-401.

Frost GS, Brynes AE, Bovill-Taylor C \& Dornhorst A (2004) A prospective randomised trial to determine the efficacy of a low glycaemic index diet given in addition to healthy eating and weight loss advice in patients with coronary heart disease. European Journal of Clinical Nutrition 58, 121-127.

Gannon MC \& Nuttal FQ (1987) Factors affecting interpretation of postprandial glucose and insulin areas. Diabetes Care 10, 759-763.

Giacco R, Parillo M, Rivellese AA, Lasorella G, Giacco A, D'Episcopo L \& Riccardi G (2000) Long-term dietary treatment with increased amounts of fibre-rich low-glycaemic index natural foods improves blood glucose control and reduces the number of hypoglycaemic events in type 1 diabetic patients. Diabetes Care 23, 1461-1466.

Gilbertson HR, Brand-Miller JC, Thorburn AW, Evans S, Chondros P \& Werther GA (2001) The effect of flexible low glycaemic index dietary advice versus measured carbohydrate exchange diets on glycaemic control in children with type 1 diabetes. Diabetes Care 24, 1137-1143.
Giovannucci E (1995) Insulin and colon cancer. Cancer Causes Control 6, 164-179.

Graham T, Sathasivam P, Roeland M, Marlo N, Greer F \& Battram D (2000) Caffeine ingestion elevates plasma insulin response in humans during an oral glucose tolerance test. Canadian Journal of Pharmacology 79, 559-565.

Granfeldt Y, Bjorck I \& Hagander B (1991) On the importance of processing conditions, product thickness and egg addition for the glycaemic and hormonal responses to pasta: a comparison with bread made from pastas' ingredients. European Journal of Clinical Nutrition 45, 489-499.

Granfeldt Y, Drews A \& Björck I (1995a) Arepas made from highamylose corn produce favourably low glucose and insulin responses in healthy humans. Journal of Nutrition $\mathbf{1 2 5}$, 459-465.

Granfeldt Y, Hagander B \& Björck I (1995b) Metabolic responses to starch in oat and wheat products. On the importance of food structure, incomplete gelatinization or presence of viscous dietary fibre. European Journal of Clinical Nutrition 49, 189-199.

Granfeldt Y, Wu X \& Björck I (2005) Determination of glycemic index (GI); some methodological aspects related to the analysis of carbohydrate load and characteristics of the previous evening meal. European Journal of Clinical Nutrition (In the Press).

Gregersen S, Rasmussen O, Winther E \& Hermansen K (1990) Water volume and consumption time: influence on the glycaemic and insulinaemic responses in non-insulin-dependent diabetic subjects. American Journal of Clinical Nutrition 52, 515-518.

Hales CN \& Randle PJ (1963) Effects of low-carbohydrate diet and diabetes mellitus on plasma concentrations of glucose, nonesterified fatty acid, and insulin during oral glucose-tolerance tests. Lancet i, 790-794.

Heine RJ, Hanning I, Morgan L \& Alberti KGMM (1983) The oral glucose tolerance test (OGTT): effect of rate of ingestion of carbohydrate and different carbohydrate preparations. Diabetes Care 6, 441-445.

Holt SH, Brand-Miller JC \& Petocz P (1996) Interrelationships among postprandial satiety, glucose and insulin responses and changes in subsequent food intake. European Journal of Clinical Nutrition 50, 788-797.

Holt SHA, Brand-Miller JC \& Petocz P (1997) An insulin index of foods: the insulin demand generated by $1000-\mathrm{kJ}$ portions of common foods. American Journal of Clinical Nutrition 66, $1264-1276$.

Järvi A, Karlström B, Granfeldt Y, Björck I, Asp N-G \& Vessby B (1999) Improved glycaemic control and lipid profile, and a normalized fibrinolytic activity on a low Gl diet in type II diabetics. Diabetes Care 22, 10-18.

Jenkins DJ, Wolever TM, Collier GR, Ocana A, Rao AV, Buckley G, Lam Y, Mayer A \& Thompson LU (1987) Metabolic effects of a low-glycaemic-index diet. American Journal of Clinical Nutrition 46, 968-975.

Jenkins DJ, Wolever TM, Jenkins AL, Giordano C, Giudici S, Thompson LU, Kalmusky J, Josse RG \& Wong GS (1986) Low glycaemic response to traditionally processed wheat and rye products: bulgur and pumpernickel bread. American Journal of Clinical Nutrition 43, 516-520.

Jenkins DJ, Wolever TM, Jenkins AL, Thorne MJ, Lee R, Kalmusky J, Reichert R \& Wong GS (1983) The glycaemic index of foods tested in diabetic patients: a new basis for carbohydrate exchange favouring the use of legumes. Diabetologia 24, 257-264.

Jenkins DJA \& Franceschi S (2001) Dietary glycaemic index and glycaemic load in breast cancer risk: a case-control study. Annals of Oncology 12, 1533-1538. 
Jenkins DJA, Ocana A, Jenkins AL, Wolever TMS, Vuksan V, Katzman L, Hollands M, Greenberg G, Corey P, Patten R, Wong GS \& Josse RG (1992) Metabolic advantages of spreading the nutrient load: effects of increased meal frequency in non-insulindependent diabetes. American Journal of Clinical Nutrition 55, 461-467.

Jenkins DJA, Wolever TMS, Ocana AM, Vuksan V, Cunnane SC, Jenkins M, Wong GS, Singer W, Bloom SR, Blendis LM \& Josse RG (1990) Metabolic effects of reducing rate of glucose ingestion by single bolus versus continuous sipping. Diabetes 39, 775-781.

Jenkins DJA, Wolever TMS, Taylor RH, Barker H, Fielden H, Baldwin JM, Bowling AC, Newman HC, Jenkins AL \& Goff DV (1981) Glycemic index of foods: a physiological basis for carbohydrate exchange. American Journal of Clinical Nutrition 34, 362-366.

Jenkins DJA, Wolever TMS, Taylor RH, Griffiths C, Krzeminska K, Lawrie JA, Bennett CM, Goff DV, Sarson DL \& Bloom SR (1982) Slow release dietary carbohydrate improves second meal tolerance. American Journal of Clinical Nutrition 35, 1339-1346.

Jungheim K \& Koschinsky T (2002) Glucose monitoring at the arm: risky delays of hypoglycemia and hyperglycemia detection. Diabetes Care 25, 956-960.

Kaplan RJ, Greenwood CE, Winocur G \& Wolever TMS (2000) Cognitive performance is associated with glucose regulation in healthy elderly persons and can be enhanced with glucose and dietary carbohydrates. American Journal of Clinical Nutrition 72, 825-836.

Keijzers GB, Galan BED, Tack CJ \& Smits P (2002) Caffeine can decrease insulin sensitivity in humans. Diabetes Care 25, 364-369.

Kelly S, Frost G, Whittaker V \& Summerbell C (2004) Low glycaemic index diets for coronary heart disease. In The Cochrane Database of Systematic Reviews, Issue 4. Chichester: John Wiley \& Sons Ltd.

Klein S, Sakurai Y, Romijn JA \& Carroll RM (1993) Progressive alterations in lipid and glucose metabolism during short-term fasting in young adult men. American Journal of Physiology 265, E801-E806.

Laville M (2004) Could glycaemic index be the basis of simple nutritional recommendations? British Journal of Nutrition 91, 803-804.

Lee BM \& Wolever TMS (1998) Effect of glucose, sucrose and fructose on plasma glucose and insulin responses in normal humans: comparison with white bread. European Journal of Clinical Nutrition 52, 924-928.

Leeds AR (2002) Glycaemic index and heart disease. American Journal of Clinical Nutrition 76, 286S-289S.

Liljeberg HG, Akerberg AKE \& Björk IME (1999) Effect of the glycemic index and content of indigestible carbohydrates of cereal-based breakfast meals on glucose tolerance at lunch in healthy subjects. American Journal of Clinical Nutrition 69, 647-655.

Liljeberg HG \& Bjorck IM (1996) Delayed gastric emptying rate as a potential mechanism for lowered glycemia after eating sourdough bread: studies in humans and rats using test products with added organic acid or an organic salt. American Journal of Clinical Nutrition 64, 886-893.

Liljeberg HG \& Bjorck IM (1998) Delayed gastric emptying rate may explain improved glycaemia in healthy subjects to a starchy meal with added vinegar. European Journal of Clinical Nutrition 52, 368-371.

Liljeberg HG, Lonner CH \& Bjorck IM (1995) Sourdough fermentation or addition of organic acids or corresponding salts to bread improves nutritional properties of starch in healthy humans. Journal of Nutrition 125, 1503-1511.
Liu PWW, Perry T \& Monro JA (2003) Glycaemic glucose equivalent: validation as a predictor of the relative glycaemic effect of foods. European Journal of Clinical Nutrition 57, 1141-1149.

Liu S, Manson JE, Stampfer MJ, Holmes MD, Hu FB, Hankinson SE \& Willett WC (2001) Dietary glycaemic load assessed by food-frequency questionnaire in relation to plasma high-densitylipoprotein cholesterol and fasting plasma triacylglycerols in postmenopausal women. American Journal of Clinical Nutrition 73, 560-566.

Liu S, Willett WC, Stampfer MJ, Hu FB, Franz M, Sampson L, Hennekens CH \& Manson JE (2000) A prospective study of dietary glycaemic load, carbohydrate intake and risk of coronary heart disease in US women. American Journal of Clinical Nutrition 71, 1455-1461.

Livesey G (2002) Approaches to health via lowering postprandial glycaemia. British Journal of Nutrition 88, 741-744.

McCleary BV \& Monaghan DA (2002) Measurement of resistant starch. Journal of AOAC International 85, 665-675.

McKeown NM, Meigs JB, Liu S, Saltzman E, Wilson PW \& Jacques PF (2004) Carbohydrate nutrition, insulin resistance and the prevalence of the metabolic syndrome in the Framingham Offspring Cohort. Diabetes Care 27, 538-546.

McKeown-Eyssen G (1994) Epidemiology of colorectal cancer revisited: are serum triglycerides and/or plasma glucose associated with risk? Cancer Epidemiology, Biomarkers and Prevention 3, 687-695.

Malkova D, Evans RD, Frayn KN, Humphreys SM, Jones PR \& Hardman AE (2000) Prior exercise and postprandial substrate extraction across the human leg. American Journal of Physiology 279, E1020-E1028.

Meyer KA, Kushi LH, Jacobs DR, Slavin J, Sellers TA \& Folsom AR (2000) Carbohydrates, dietary fibre and incident type 2 diabetes in older women. American Journal of Clinical Nutrition 71, 921-930.

Mikines KJ, Sonne B, Farrell PA, Tronier B \& Galbo H (1988) Effect of physical exercise on sensitivity and responsiveness to insulin in humans. American Journal of Physiology 254, E248-E259.

Monro J (2003) Redefining the glycaemic index for dietary measurement of postprandial glycemia. Journal of Nutrition 133, 4256-4258.

Monro JA (1999a) Food exchange tables for control of postprandial glycemia. Journal of the New Zealand Dietetic Association 53, 11-21.

Monro JA (1999b) Available carbohydrate and glycaemic index combined in new data sets for managing glycaemia and diabetes. Journal of Food Composition and Analysis 12, 71-82.

Monro JA (2002) Glycaemic glucose equivalents: combining carbohydrate content, quantity and glycaemic index of foods for precision in glycemia management. Asia Pacific Journal of Clinical Nutrition 11, 217-225.

Monro JA \& Williams M (2000) Concurrent management of postprandial glycemia and nutrient intake using glycaemic glucose equivalents, food composition data and computer assisted design. Asia Pacific Journal of Clinical Nutrition 9, $67-73$.

Nuttall FQ, Gannon M, Wald J \& Ahmed M (1985) Plasma glucose and insulin profiles in normal subjects ingesting diets of varying carbohydrate, fat and protein content. Journal of the American College of Nutrition 4, 437-450.

Opperman AM, Venter CS, Oosthuizen W, Thompson RL \& Vorster HH (2004) Meta-analysis of the health effects of using the glycaemic index in meal-planning. British Journal of Nutrition 92, 367-381.

Ostman EM, Liljeberg Elmstahl HG \& Bjorck IM (2001) Inconsistency between glycaemic and insulinaemic responses 
to regular and fermented milk products. American Journal of Clinical Nutrition 74, 96-100.

Pawlak DB, Ebbeling CB \& Ludwig DS (2002) Should obese patients be counselled to follow a low glycemic index diet? Yes. Obesity Reviews 3, 235-243.

Pi-Sunyer FX (2002) Glycemic index and disease. American Journal of Clinical Nutrition 76, 290S-298S.

Raben A (2002) Should obese patients be counselled to follow a low glycemic index diet? No. Obesity Reviews 3, 245-256.

Rizkalla SW, Taghrid L, Laromiguiere M, Huet D, Boillot J, Rigoir A, Elgrably F \& Slama G (2004) Improved plasma glucose control, whole-body glucose utilization, and lipid profile on a low-glycemic index diet in type 2 diabetic men: a randomized controlled trial. Diabetes Care 27, 1866-1872.

Robertson MD, Henderson RA, Vist GE \& Rumsey RDE (2002) Extended effect of evening meal carbohydrate/fat ratio on fasting and postprandial substrate metabolism. American Journal of Clinical Nutrition 75, 505-510.

Salmeron J, Manson JE, Stampfer MJ, Colditz GA, Wing AL \& Willett WC (1997a) Dietary fiber, glycaemic load, and risk of non-insulin-dependent diabetes mellitus in women. Journal of the American Medical Association 277, 472-477.

Salmeron J, Ascherio A, Rimm EB, Colditz GA, Spiegelman D, Jenkins DJ, Stampfer MJ, Wing AL \& Willett WC (1997b) Dietary fiber, glycaemic load, and risk of NIDDM in men. Diabetes Care 20, 545-550.

Samra JS, Clark ML, Humphreys SM, Macdonald IA \& Frayn KN (1996) Regulation of lipid metabolism in adipose tissue during early starvation. American Journal of Physiology 271, E541-E546.

Schauberger G, Brinck US, Suldner G, Spaethe R, Niklas L \& Otto $\mathrm{H}$ (1978) Exchange of carbohyrates according to their effect on blood glucose. Diabetes 26, 415 .

Schulz KF \& Grimes DA (2002a) Allocation concealment in randomised trials: defending against deciphering. Lancet 359, 614-618.

Schulz KF \& Grimes DA (2002b) Generation of allocation sequences in randomised trials: chance, not choice. Lancet 359, $515-519$.

Schulz KF \& Grimes DA (2002c) Unequal group sizes in randomised trials: guarding against guessing. Lancet 359, 966-970.

Shelmet JJ, Reichard GA, Skutches CL, Hoeldtke RD, Owen OE \& Boden G (1988) Ethanol causes acute inhibition of carbohydrate, fat, and protein oxidation and insulin resistance. Journal of Clinical Investigations 81, 1137-1145.

Sievenpiper JL, Jenkins DJ, Josse RG \& Vuksan V (2001) Dilution of 75 -g oral glucose tolerance test improves overall tolerability but not reproducibility in subjects with different body compositions. Diabetes Research and Clinical Practice 51, 87-95.

Siler SQ, Neese RA, Christiansen MP \& Hellerstein MK (1998) The inhibition of gluconeogenesis following alcohol in humans. American Journal of Physiology 275, E897-E907.

Slabber M, Barnard HC, Kuyl JM, Dannhauser A \& Schall R (1994) Effects of low-insulin-response, energy-restricted diet on weight loss and plasma insulin concentrations in hyperinsulinaemic obese females. American Journal of Clinical Nutrition 60, $48-53$.

Slattery ML, Benson J, Berry TD, Duncan D, Edwards SL, Caan BJ \& Potter JD (1997) Dietary sugar and colon cancer. Cancer Epidemiology, Biomarkers and Prevention 6, 677-685.

Sugiyama M, Tang AC, Wakaki Y \& Koyama W (2003) Glycaemic index of single and mixed meal foods among common Japanese foods with white rice as a reference food. European Journal of Clinical Nutrition 57, 743-752.
Tavani A, Bosetti C, Negri E, Augustin LS, Jenkins DJ \& La Vecchia C (2003) Carbohydrates, dietary glycaemic load and glycaemic index, and risk of acute myocardial infarction. Heart 89, $722-726$.

Thomas DE, Brotherhood JR \& Brand JC (1991) Carbohydrate feeding before exercise: effect of glycaemic index. International Journal of Sports Medicine 12, 180-186.

Thorburn A, Muir J \& Proietto J (1993) Carbohydrate fermentation decreases hepatic glucose output in healthy subjects. Metabolism 42, 780-785.

Thorne MJ, Thompson LU \& Jenkins DJ (1983) Factors affecting starch digestibility and the glycaemic response with special reference to legumes. American Journal of Clinical Nutrition 38, 481-488.

Torsdottir I \& Anderson H (1989) Effect on the postprandial glycaemic level of the addition of water to a meal ingested by healthy subjects and type 2 (non-insulin-dependent) diabetic patients. Diabetologia 32, 231-235.

Tsetsonis NV \& Hardman AE (1996) Reduction in postprandial lipemia after walking: influence of exercise intensity. Medicine and Science in Sports and Exercise 28, 1235-1242.

Tsetsonis NV, Hardman AE \& Mastana SS (1997) Acute effects of exercise on postprandial lipemia: a comparative study in trained and untrained middle-aged women. American Journal of Clinical Nutrition 65, 525-533.

van Dam RM, Visscher AW, Feskens EJ, Verhoef P \& Kromhout D (2000) Dietary glycaemic index in relation to metabolic risk factors and incidence of coronary heart disease: the Zutphen Elderly Study. European Journal of Clinical Nutrition 54, 726-731.

van Der Valk PR, van Der Schatte O, Steding I, Wientjes K-JC, Schoonen AJ \& Hoogenberg K (2002) Alternative-site blood glucose measurement at the abdomen. Diabetes Care 25, $2114-2115$.

Walker AR \& Walker BF (1984) Glycaemic index of South African foods determined in rural blacks - a population at low risk of diabetes. Human Nutrition Clinical Nutrition 38, 215-222.

Willett W, Manson J \& Liu S (2002) Glycaemic index, glycaemic load, and risk of type 2 diabetes. American Journal of Clinical Nutrition 76, 274S-280S.

Williams CM \& Jackson KG (2002) Inulin and oligofructose: effects on lipid metabolism from human studies. British Journal of Nutrition 87, S261-S264.

Wolever TM (1990a) The glycaemic index. World Review of Nutrition and Dietetics 62, 120-185.

Wolever TM \& Jenkins DJ (1986) The use of the glycaemic index in predicting the blood glucose response to mixed meals. American Journal of Clinical Nutrition 43, 167-172.

Wolever TM, Jenkins DJ, Collier GR, Ehrlich RM, Josse RG, Wong GS \& Lee R (1988a) The glycaemic index: effect of age in insulin dependent diabetes mellitus. Diabetes Research 7, $71-74$.

Wolever TM, Jenkins DJ, Josse RG, Wong GS \& Lee R (1987) The glycaemic index: similarity of values derived in insulin-dependent and non-insulin-dependent diabetic patients. Journal of the American College of Nutrition 6, 295-305.

Wolever TM, Jenkins DJ, Ocana AM, Rao VA \& Collier GR (1988b) Second-meal effect: low-glycaemic-index foods eaten at dinner improve subsequent breakfast glycaemic response. American Journal of Clinical Nutrition 48, 1041-1047.

Wolever TM, Nuttall FQ, Lee R, Wong GS, Josse RG, Csima A \& Jenkins DJ (1985) Prediction of the relative blood glucose response of mixed meals using the white bread glycaemic index. Diabetes Care 8, 418-428.

Wolever TMS (1990b) Metabolic effects of continuous feeding. Metabolism 39, 947-951. 
Wolever TMS (2004a) Comment on the validity of glycaemic glucose equivalent. European Journal of Clinical Nutrition 58, 1672-1673.

Wolever TMS (2004b) Effect of blood sampling schedule and method calculating the area under the curve on validity and precision of glycaemic index values. British Journal of Nutrition 91, 295-300.

Wolever TMS, Björck I, Brand-Miller J, Brighenti F, Holt S, Mann J, Perry TL, Venter C, Granfeldt Y, Xaomei Wu \& Vorster H (2003) Determination of the glycaemic index of foods: interlaboratory study. European Journal of Clinical Nutrition 57, 475-482.

Wolever TMS \& Bolognesi C (1996a) Source and amount of carbohydrate affect postprandial glucose and insulin in normal subjects. Journal of Nutrition 126, 2798-2806.

Wolever TMS \& Bolognesi C (1996b) Prediction of glucose and insulin responses of normal subjects after consuming mixed meals varying in energy, protein, fat carbohydrate and glycaemic index. Journal of Nutrition 126, 2807-2812.

Wolever TMS \& Bolognesi C (1996c) Time of day influences relative glycaemic effect of foods. Nutrition Research 16, $381-384$.

Wolever TMS, Campbell JE, Geleva D \& Anderson GH (2004) High-fiber cereal reduces postprandial insulin responses in hyperinsulinemic but not normoinsulinemic subjects. Diabetes Care 27, 1281-1285.

Wolever TMS, Chiasson JL, Hunt JA, Palmason C, Ross SA \& Ryn EA (1998) Similarity of relative glycaemic but not relative insulinaemic responses in normal, IGT and diabetic subjects. Nutrition Research 18, 1667-1676.
Wolever TMS, Cohen Z, Thompson LU, Thorne MJ, Jenkins MJA, Prokipchuk EJ \& Jenkins DJA (1986a) Ileal loss of available carbohydrate in man: comparison of a breath hydrogen method with direct measurement using a human ileostomy model. American Journal of Gastroenterology 81, 115-122.

Wolever TMS, Jenkins DJA, Jenkins AL \& Josse RG (1991) The glycaemic index: methodology and clinical implications. American Journal of Clinical Nutrition 54, 846-854.

Wolever TMS, Jenkins DJA, Kalmusky J, Jenkins AL, Giordano C, Giudici S, Josse RG \& Wong GS (1986b) Comparison of regular and parboiled rices: explanation of discrepancies between reported glycaemic responses to rice. Nutrition Research $\mathbf{6}$, 349-357.

Wolever TMS \& Mehling C (2002) High-carbohydrate/lowglycaemic index dietary advice improves glucose disposition index in subjects with impaired glucose tolerance. British Journal of Nutrition 87, 477-487.

Wolever TMS \& Mehling C (2003) Long-term effect of varying source or amount of dietary carbohydrate on postprandial plasma glucose, insulin, triacylglycerol and free fatty acid concentrations in subjects with impaired glucose tolerance. American Journal of Clinical Nutrition 77, 612-621.

Wolever TMS, Vorster HH, Björk I, Brand-Miller J, Brighenti F, Mann JI, Ramdath DD, Granfeldt Y, Holt S, Perry TL, Venter C $\& \mathrm{Wu} X$ (2002) Determination of the glycaemic index of foods: interlaboratory study. European Journal of Clinical Nutrition 57, 475-482.

Young KWH \& Wolever TMS (1998) Effect of volume and type of beverage consumed with a standard test meal on postprandial blood glucose responses. Nutrition Research 18, 1857-1863. 